\title{
A laboratory investigation into the aggregation efficiency of small ice crystals
}

\author{
P. J. Connolly ${ }^{1}$, C. Emersic ${ }^{1}$, and P. R. Field ${ }^{2}$ \\ ${ }^{1}$ School of Earth, Atmospheric and Environmental Sciences, The University of Manchester, Manchester, UK \\ ${ }^{2}$ Met Office, Exeter, UK \\ Correspondence to: P. J. Connolly (p.connolly@man.ac.uk)
}

Received: 12 August 2011 - Published in Atmos. Chem. Phys. Discuss.: 14 September 2011

Revised: 7 February 2012 - Accepted: 12 February 2012 - Published: 21 February 2012

\begin{abstract}
The aggregation of ice crystals and its temperature dependence is studied in the laboratory using a large ice cloud chamber. This process is important to the evolution of ice clouds in earth's atmosphere, yet there have been relatively few laboratory studies quantifying this parameter and its dependence on temperature. A detailed microphysical model is used to interpret the results from the experiments and derive best estimates for the aggregation efficiency as well as error bars. Our best estimates for the aggregation efficiency, at temperatures other than $-15^{\circ} \mathrm{C}$, (in the interval $-30 \leq T \leq 5^{\circ} \mathrm{C}$ ) are mostly in agreement with previous findings, which were derived using a very different approach to that described here. While the errors associated with such experiments are reasonably large, statistically, at temperatures other than -15 , we are able to rule out aggregation efficiencies larger than 0.5 at the 75 th percentile and rule out nonzero values at $-15^{\circ} \mathrm{C}$, whereas at $-15^{\circ} \mathrm{C}$ we can rule out values higher than 0.85 and values lower than 0.35 . The values of the aggregation efficiency shown here may be used in model studies of aggregation, but care must be taken that they only apply for the initial stages of aggregate growth, with humidities at or close to water saturation, and for particles up to a maximum size of $\sim 500 \mu \mathrm{m}$. They may therefore find useful application for modelling supercooled mid-level layer clouds that contain ice crystals, which are known to be important radiatively.
\end{abstract}

\section{Introduction}

The formation of snowflakes in earth's atmosphere frequently involves th ecoming together and subsequent aggregation of two or more ice particles. Many in-situ observations of ice cloud microphysics indeed confirm that ice-ice aggregation takes place in clouds from temperatures that are just below $0{ }^{\circ} \mathrm{C}$ to temperatures as cold as $-60^{\circ} \mathrm{C}$ (e.g. Connolly et al., 2005; Crosier et al., 2011; Field and Heymsfield, 2003) and consequently this process is fundamental to the generation of large precipitation particles (Heymsfield, 1986; Sölch and Kärcher, 2011); yet, so far there have been surprisingly few studies of ice-ice aggregation that can be used to quantify the rates of growth of ice by aggregation in clouds. The reason for this is probably due to the heterogeneity of ice crystals observed in nature, for instance: (i) particles of the same mass do not necessarily have the same velocity due to the variation in ice crystal shapes, meaning that it is not really relevant to study the interaction of ice crystals of merely different mass (as has been done for water drops); (ii) aggregation is important to particles of many different sizes, but particles of similar sizes play an important role in developing aggregates in the initial stages of their growth. Since particles of similar size have similar fall speeds, a long distance is required for them to fall before enough ice-ice collections can be acquired for accurate estimates of aggregation rates to be made.

In order to improve the representation of aggregation within models, the quantity that is usually investigated and used as input to models is the collection efficiency between two ice crystals that are settling at their terminal velocity. 
In this paper we shall refer to this as the aggregation efficiency, $E_{\mathrm{agg}}$. Under the assumption that the ice crystals are falling under gravity one can write down the so called hydrodynamic kernel (Pruppacher and Klett, 1997), K, which describes the aggregation efficiency multiplied by the volume of air "swept-out" by two ice particles falling at different velocities in a reference frame of either one of the particles:

$K(i, j)=\left(r_{i}+r_{j}\right)^{2} \pi E_{\mathrm{agg}}\left|\mathrm{v}_{i}-\mathrm{v}_{j}\right|$

where $i$ and $j$ subscripts refer to particle $i$ or particle $j ; r$ is the "radius" of the particle; $v$ is the terminal velocity of the particle and $E_{\text {agg }}$ is the aggregation efficiency, which is equal to the product of the collision efficiency, $E_{c}$, and the sticking efficiency, $E_{s}$; hence: $E_{\mathrm{agg}}=E_{c} \times E_{s}$. In the case of ice particles, the radius is not a well defined quantity as they are not spherical; however, if we take the time-averaged area of the crystal normal to the direction it is falling in as being $A$, then we can write an approximate form of the kernel to be:

$K(i, j)=\left(A_{i}^{0.5}+A_{j}^{0.5}\right)^{2} E_{\mathrm{agg}}\left|\mathrm{v}_{i}-\mathrm{v}_{j}\right|$

here, $A$ is the projected area of the particle normal to the fall direction, which raised to the power of 0.5 represents the average 'radius' normal to the flow. Note that multiplying Eq. (2) by the number concentration of particles of type $j$ gives the number of aggregations of particles of type $j$ on to particle $i$ per second.

To date several methods have been employed to try and quantify $E_{\text {agg }}$ in Eqs. (1) and (2), ranging from aircraft studies to laboratory studies. The aircraft studies generally use a method called a Lagrangian spiral descent, whereby the aircraft ascends to the top of an ice cloud layer and descends at a rate approximately equal to the terminal fall speed of the ice particles, while banking; therefore performing a spiral descent through the cloud layer (Field and Heymsfield, 2003; Field et al., 2006b). Throughout the descent of the aircraft the ice particle size distribution is measured constantly using a 2-D shadow probe, such as the two-dimensional cloud probe (2D-C), the Cloud Imaging Probe (CIP) or the twodimensional stereoscopic cloud probe (2D-S). These methods have their obvious uncertainties, which include experimental uncertainty as well as possible sampling artefacts such as particles breaking up on the inlets of the probes (McFarquhar et al., 2007; Field et al., 2003, 2006a; Lawson, 2011), but are a useful guide to what the aggregation efficiency is for naturally grown ice particles nonetheless. By applying a bulk microphysical model (described by Passarelli, 1978; Mitchell, 1988) to the observed data Field and Heymsfield (2003) presented the calculated $E_{\text {agg values for }}$ 13 such Lagrangian spiral descents observed over 3 field campaigns. Their estimates for $E_{\text {agg }}$ tend to be around 0.3, but values of 0.1 also gave reasonable agreement with the observations; important to note was that there was no strong dependence of the aggregation efficiency on temperature.
Mitchell et al. (1996) found from a case study in cirrus clouds that the cloud-averaged $E_{\text {agg }}$ was $\sim 0.5$. More recently, Mitchell et al. (2006) applied a new snow growth model to calculate that in a case dominated by dendrites at cloud top $E_{\text {agg }} \cong 0.55$ whereas in other cases $E_{\text {agg }} \cong 0.07$. This body of work therefore suggests that intricate dendrites have higher aggregation efficiencies than more simple crystals.

Field et al. (2006b) circumvented the bulk modelling approach used by previous researchers by using a bin microphysics model approach to calculate aggregation rates in a layer cloud observed with a Lagrangian spiral descent. Their findings were similar to that of Field and Heymsfield (2003) in that $E_{\text {agg }} \sim 0.1$ produced the best agreement with observations at temperatures from -11 to $-3{ }^{\circ} \mathrm{C}$.

The laboratory methods have used a variety of techniques to quantify the aggregation efficiency and its dependence on temperature. Perhaps the most comprehensive of these done to date was that by Hosler and Halgren (1960) who investigated the aggregation efficiency and it's temperature dependence by holding a large stationary ice target (which had an initial diameter of $127-360 \mu \mathrm{m}$ ) and drawing smaller ice crystals of maximum dimension $\sim 30 \mu \mathrm{m}$ in an air stream past this large ice target. Some of the small ice crystals that were aspirated past the large target collided with the target and stuck (aggregated), while some rebounded, therefore Hosler and Halgren were able to quantify the aggregation efficiency by measuring the increase in particle mass with time, while knowing the speed of the airstream, the mass of individual crystals and their number concentration; thus, the rate of mass increase of the large ice target can be described by:

$R=\frac{v_{\text {air }} \times m_{\text {small }} \times n_{\text {small }} \times E_{\text {agg }}}{\Delta t}$

where $R$ is the rate of increase in mass of the large ice particle, $v_{\text {air }}$ is the velocity of the air stream, $m_{\text {small }}$ and $n_{\text {small }}$ are the mass and the number concentration of the small ice crystals respectively, $R$ is the rate of mass increase of the large particle and $\Delta t$ is the time interval over which $R$ is measured. The aggregation efficiency, $E_{\mathrm{agg}}$, was then inferred by making it the subject of Eq. (3). Hosler and Halgren's study showed an apparent maximum at $-15^{\circ} \mathrm{C}$ of around $0.1-0.2$, which reduced smoothly at temperatures either side of $-15^{\circ} \mathrm{C}$ to $0.06-0.03$ at -5 to $-25^{\circ} \mathrm{C}$, hence this is in contrast to the aircraft derived values of Field and Heymsfield (2003) mentioned above, which showed little variation with temperature. It should be noted that in Hosler and Halgren's experiments the size of the ice crystals in the airstream were only $7-18 \mu \mathrm{m}$ in diameter, which probably ruled out any branching growth on the ice crystals, and rendered particle interlocking as an effective aggregation mechanism to be less important.

The findings of Hosler and Halgren (1960) seem somewhat contradictory to earlier work (Hosler et al., 1957) where the force required to separate two ice "spheres" and its 
dependence on temperature was measured. Hosler et al. (1957) clearly showed that this force was a monotonically decreasing function of the temperature below the melting point of ice - no maximum at $-15^{\circ} \mathrm{C}$ was evident. Furthermore they showed that the measured force increases dramatically when the vapour pressure in the air surrounding the ice spheres approaches ice saturated conditions, which suggests that ice growth between the two ice spheres strengthened the ice "neck" between the spheres at the point of contact. It has to be said that the ice spheres were held in contact for $1 \mathrm{~min}$ before an attempt was made to separate them. Clearly ice crystals falling in the atmosphere and coming in contact are not afforded this length of time and so it is hard to link the results of Hosler et al. (1957) to a more realistic situation. Other authors have hypothesized that the interlocking of ice crystals is one mechanism that can allow them to come in contact for long enough for sintering (see Hobbs, 1965) to take place (e.g. Heymsfield, 1986), which seems entirely reasonable, since under water saturated conditions, dendrites are observed at $-15^{\circ} \mathrm{C}$, while crystals tend to be less spatially orientated when grown from the vapour at both higher and lower temperatures (Libbrecht, 2005).

In this paper we use a more realistic experimental set-up to Hosler and Halgren (1960) to study ice crystals falling under their terminal velocity, whilst growing under water saturation and subsequently aggregating. We use this set-up to attempt to better quantify the aggregation efficiency of ice crystals in the early stages of growth. The questions that we address are:

- Is the finding that $E_{\text {agg }}$ has a weak dependence on temperature reproduced by a realistic laboratory set-up?

- Is the slight maximum in $E_{\text {agg }}$ found at $-15^{\circ} \mathrm{C}$ by Hosler and Halgren (1960) applicable when ice crystals are falling in free-fall and growing from the vapour to sizes more typical of the atmosphere, or is this an artefact of their experiment?

We note that in the atmosphere the electric field may influence aggregation efficiencies (e.g. Connolly et al., 2005), but we do not attempt to quantify the effect of the electric field here. We also note that the aggregation efficiency may depend on the complexity of the particles (for example how many edges are available to allow particle interlocking) again this study does not address this complex issue as we only deal with the initial stages of aggregation. Another effect that is known to occur in the atmosphere is the break-up of large ice aggregates (Lo and Passarelli, 1982); however, in this paper we only study aggregates smaller than $600 \mu \mathrm{m}$ and therefore have not taken this process into consideration. It is noted that in some cases "wake-capture" may be important, where an ice crystal may be captured that is not within the volumetric sweep-out of two ice particles; while this study does not directly address this and other issues, any of the aforementioned physical processes, except the effect of the electric field, will be represented in the bulk value of $E_{\mathrm{agg}}$ together with the assumed form of the hydrodynamic kernel.

\section{Experimental method}

In order to generate data for this study experiments were conducted in the Manchester Ice Cloud Chamber (MICC), which offers a $10 \mathrm{~m}$ high stainless steel tube, $1 \mathrm{~m}$ in diameter that can be used to perform studies of cloud processes; the tube is housed in three separate cold rooms stacked on top of each other, which reside on three stories of the $\mathrm{Si}$ mon Building at the University of Manchester (UoM) and completely enclose the steel tube. The temperature within the cold rooms can be reduced controllably from room temperature to $-50^{\circ} \mathrm{C}$, and the chamber can be pressure sealed and evacuated to simulate conditions found in the upper troposphere. Further details about the facility are available at http://data.cas.manchester.ac.uk/micc/micc.htm.

The details of how the experiments were performed will now be explained. A port hole at the bottom of the chamber was left open to allow the cold room air to enter the stainless steel tube so that under conditions of equilibrium the air inside the tube had the same temperature as the cold room set point. Clouds of supercooled drops were generated using a water boiler, which was placed at the bottom of the steel tube and the steam it produced entered the stainless steel tube through a copper pipe of $15 \mathrm{~mm}$ diameter, which extended to $1.6 \mathrm{~m}$ into the chamber. The water boiler was switched on until the point at which the water started to boil, and then the power was set to $\sim 440 \mathrm{~W}$, which defines the rate of evaporation of the water. The steam was allowed to mix, by buoyancy and turbulent mixing, into the stainless steel tube at this setting for $10 \mathrm{~min}$, to allow for a reasonably uniform liquid water content within the chamber; it was found that this generated liquid water contents lower than approximately $5 \mathrm{~g} \mathrm{~m}^{-3}$ inside the tube, although the actual amount depended on the temperature of the experiment. The heat from the boiler increased the temperature of the air within the stainless steel tube by a few degrees typically, but then stabilised at a constant temperature.

The temperature of the cloud was measured at three points along the length of the chamber using calibrated platinum resistance thermometers, which were positioned to measure the temperature $\sim 30 \mathrm{~cm}$ in from the inner wall of the steel tube. It was found that the temperature of the cloud rapidly cooled to the temperature of the cold room, typically within a minute or so. Variations in temperature along the length of the tube were found to be less than $1^{\circ} \mathrm{C}$, which was deemed to be sufficiently small to obtain meaningful results, given other errors associated with this set of experiments.

Two CPI probes were used to measure the cloud properties within the chamber, with one positioned at the base of the steel tube and the other approximately half way up the chamber. Air was sampled through the probes at a rate of 
$1001 \mathrm{~min}^{-1}$, which corresponded to an airspeed of approximately $4 \mathrm{~m} \mathrm{~s}^{-1}$ through the sampling area of the probes. The model of CPI that we operated within the chamber took 40 images per second of particles that passed through a small sample volume $\left(\sim 30 \mathrm{~mm}^{3}\right)$; the actual size of the sample volume depends on factors such as the laser power and the size and shape of the particle, and depending on the particles position within the sample volume the CPI may oversize the particle by up to a factor of 3 or 4 (Connolly et al., 2007). Consequently both probes were subjected to a detailed calibration procedure and corrections were produced based on the method published in Connolly et al. (2007) - this method was found to work well for both probes. Concerns have been raised that the CPI probe may suffer from possible shattering of ice crystals on the probe inlet, which then appear as high ice crystal concentrations in the probe data (Schwarzenboeck et al., 2009). This problem is not expected to be an issue for the experiments in the laboratory, where impact velocities between the inlet and ice crystals are one to two orders of magnitude lower than on an aircraft. We therefore believe that the CPI adequately serves laboratory use.

All of the experiments described herein were at temperatures higher than $-30^{\circ} \mathrm{C}$ and due to the fact that the air was free of Ice Nuclei (IN) we did not observe any ice with either of the CPI's. In order to initiate ice within the cloud of drops inside the steel tube we used a solenoid valve and a compressed air line ( 2000 mbar over pressure), that was fitted to a port hole that was $50 \mathrm{~cm}$ from the top of the steel tube. Opening the valve briefly allows the compressed air to exit from the pipe, and then expand to the ambient pressure (1000 mbar), which results in adiabatic cooling of this small volume of air. The amount of cooling can be estimated by conserving dry potential temperature:

$\theta=T_{\text {cooled }}=T_{\text {initial }}\left(\frac{1000}{1000+2000}\right)^{R / c p}$

where $R=287 \mathrm{~J} \mathrm{~kg}-1 \mathrm{~K}^{-1}$ and $c p=1005 \mathrm{~J} \mathrm{~kg}-1 \mathrm{~K}^{-1}$. Making $T_{\text {cooled }}$ the subject of the equation and using typical experimental temperatures for $T_{\text {initial }}$ yields that the air is cooled to $\sim-80^{\circ} \mathrm{C}$. This is a theoretical maximum cooling that can be expected and in reality it will be less than this, nevertheless the brief expansion resulted in homogeneous nucleation of ice in the liquid drops that were present and also homogeneous condensation of new drops, followed by their freezing and ice crystals were observed, by the two CPI's, to fall through the cloud, growing from the vapour and by ice-ice aggregation.

The ice crystals produced fell downward through the chamber and number concentrations and size distributions were measured firstly by the mid-level CPI, and finally by the lower CPI. The vertical separation between the two probes was $3.8 \mathrm{~m}$ and the time elapsed between detection of $1 \mathrm{st}$ ice at the mid-level CPI and 1st ice at the lower CPI was approximately $100 \mathrm{~s}$, which suggests a fall speed of $\sim 4 \mathrm{~cm} \mathrm{~s}^{-1}$. The ice crystals falling grew at water saturation and depleted the available vapour by the Bergeron-Findeisen (B-F) process so that ice crystals falling behind the leading edge grew at lower supersaturations and were smaller.

In this study we solely concentrated on the initial concentration pulse in which the ice crystals grew at water saturation. Ice crystals measured with the CPIs were observed to give a pulse in concentration at the mid-level CPI and then at the bottom CPI. During all experiments, the boiler was active to continuously supply vapour and droplets to the cloud. The inside walls of the cloud chamber were coated with ice for all experiments.

\section{Data interpretation}

In order to assess the suitability of the hydrodynamic kernel we assessed whether differential sedimentation or diffusion dominated the aggregation process. The collision kernel due to diffusion is (see Jacobson, 1999):

$K^{\text {diffusion }}=4 \pi\left(r_{1}+r_{2}\right)\left(\kappa_{1}+\kappa_{2}\right)$

where $\kappa=\frac{k T}{6 \pi \eta r}$ is the diffusion coefficient of the particle and Boltzmann's constant, $k=1.38 \times 10^{-23} \mathrm{~m}^{2} \mathrm{~kg} \mathrm{~s}^{-1} \mathrm{~K}^{-1}$; and the dynamic visocity of air $\eta \sim 1.6 \times 10^{-5} \mathrm{~kg} \mathrm{~m}^{-1} \mathrm{~s}^{-1}$.

The collision kernel due to differential sedimentation is approximately (i.e. Eq. 1):

$K^{\text {sedimentation }}=\pi\left(r_{1}+r_{2}\right)^{2} \Delta V$

where $\Delta V \sim 0.1 \mathrm{~m} \mathrm{~s}^{-1}$ is the difference in fall speed between two colliding crystals.

For $T=250 \mathrm{~K} ; \eta=1.6 \times 10^{-5} \mathrm{~kg} \mathrm{~m}^{-1} \mathrm{~s}^{-1} ; r_{1}=50 \mu \mathrm{m}$ and $r_{2}=25 \mu \mathrm{m}$, then $\frac{K^{\text {sedimentation }}}{K^{\text {diffusion }}} \sim 10^{8}$. Hence, sedimentation is completely dominant relative to Brownian collisions.

\subsection{Modelling}

In order to interpret the data from our experiments we have developed a numerical model called the Aerosol-CloudPrecipitation Interaction Model (ACPIM). ACPIM has been used as a box model to interpret results from ice nucleation experiments (Connolly et al., 2009) and also as a 1-D column model to investigate the impact of aerosols on warm cloud microphysics and precipitation (Dearden, 2009; Dearden et al., 2011). Here we describe the details of the model that are relevant to this study, specifically those that affect the growth of ice particles.

\subsubsection{Description of microphysics within the model}

Firstly, all microphysical variables are held on a 1-D Eulerian grid. For both liquid and ice particles we use a 2-D grid, which splits up particle "number concentration" categories by their water mass and their aerosol mass (Bott, 2000). The 
aerosol size grid starts and ends at $2 \mathrm{~nm}$ and $10 \mathrm{~cm}$ respectively and the mass of each sucessive bin is $\sqrt{2}$ times the previous bin, which results in 154 bins. The water mass grid spans $1 \times 10^{-22}$ to $1 \mathrm{~kg}$ and each sucessive bin is $\sqrt{2}$ times the previous bin, which results in 147 bins. This may seem excessive; however, our aim is to be able to model all types of hydrometeor, from cloud drops to large hail stones. The advantage of the 2-D bin structure is that one can simulate the range of aerosol masses that are present after collision and coalescence has taken place. Our bin grid is slightly different to that of Bott (2000) in that the aerosol bins are single moment (like Bott, 2000); however, the water grid has the option to be double moment, which reduces numerical diffusion when solving for growth by vapour diffusion and collision-coalescence. We have experimented with two double moment schemes including the "hybrid bin" scheme of Chen and Lamb (1994b) and the "moving centre" approach (Jacobson, 1999); however, we find the "moving centre" approach to be adequate for our purpose and chose to use it based on its simplicity.

We make no artificial separation between aerosols, cloud drops or rain, save for the fact that they exist in different bins on the model grid. The saturation vapour pressure of all liquid particles is calculated based on a detailed thermodynamics model, also developed at UoM, called the Aerosol Diameter Dependent Equilibrium Model (ADDEM) - Topping et al. (2005a,b). This saturation vapour pressure is used as input into the droplet growth equation (with ventilation coefficients from Pruppacher and Rasmussen, 1979). The collision efficiency used in the stochastic collection equation are taken from the data in the table by Hall (1980) and interpolated onto the mass grid of ACPIM. In these calculations we have not taken into account the coalescence efficiency, and subsequent break-up of drops following collision.

The ice particle grid is set up in the same way as the liquid water grid, except that it holds average ice particle properties in each bin. The average ice particle properties that we hold are: (i) the ice particle crystal volume; (ii) the number of monomer ice crystals within an ice bin; (iii) the crystal aspect ratio; and (iv) the mass of rime on the ice particle.

The ice particle crystal volume changes in the following way: when droplets freeze to form ice crystals their density is set to that of pure ice $\sim 910 \mathrm{~kg} \mathrm{~m}^{-3}$; following growth by diffusion (with ventilation coefficients from Ji and Wang, 1999) the crystal density changes based on the model described by Chen and Lamb (1994a) and the volume added to the crystal is equal to the change in its mass divided by the "deposition density". As described by Chen and Lamb, the density of deposited vapour on the crystal decreases as the vapour excess increases over $0.05 \mathrm{~g} \mathrm{~m}^{-3}$; this reflects the fact that crystals exhibit "branching" at high supersaturations (Libbrecht, 2005, and cf. hollowed columns and dendrites).

The crystal aspect ratio is assumed to be the same for all monomer crystals within an ice aggregate. After droplets freeze they form isometric ice crystals, but soon change their aspect ratio based on a parameter called the inherent growth ratio, $\Gamma(T)$ (see Chen and Lamb, 1994a, for details). This reflects the fact that the deposition coefficient on both the $c$ and $a$ crystallographic faces change relative to another with temperature (Libbrecht, 2005). There is recent experimental evidence that facets develop due to this difference in the deposition coefficient on each of the crystallographic faces at low supersaturations, however other factors, such as dislocations and other defects may affect faceting at higher supersaturations (Libbrecht, 2005). Nevertheless the Chen and Lamb (1994a) model parameterises the fact that columnar shapes are likely to grow at $-5^{\circ} \mathrm{C}$, planar crystals at $-15^{\circ} \mathrm{C}$ and columns at $-25^{\circ} \mathrm{C}$.

The number of monomer crystals in an ice particle is solved for within the stochastic collection equation between ice crystals. A collision and collection between two ice particles transfers total monomer number from both interacting particles into the new ice category that is created. This is also the case for particle volume, crystal aspect ratio and the mass of rime on the ice particles. The mass of rime on the ice particles is calculated from the stochastic collection equation between liquid and ice particles.

The average particle properties that are carried in the model turn out to be very useful in defining the growth rate and fall-speeds of the ice crystals. For instance, storing the number of monomers within an aggregate is useful in defining the particle's maximum dimension, since ice aggregates are known to have a fractal-like dimension that is close to 2 (Westbrook et al., 2004; Schmitt and Heymsfield, 2010) and therefore have masses describe by a law of the kind:

$m\left(D_{\max }\right)=a \times D_{\max }^{b}$

where $m$ is the particle mass, $D_{\max }$ is the maximum dimension of the particle, $b=\sim 2$ and $a$ is unknown. We have made a rather ad-hoc assumption that the first two monomers stick together end-on-end with an angle of $45^{\circ}$ between their maximum dimensions, which results in $D_{\max }=\sqrt{2} \times D_{\text {monomer }}$. This allows us to define $a$ in Eq. (7) and therefore by making $D_{\max }$ the subject of this equation it allows us to define the maximum dimension of all ice particles.

Our motivation to be able to define the maximum dimension stems from the studies by Westbrook et al. (2008); Field et al. (2007) who have shown that once there is more than one ice crystal within an ice particle the capacitance of the ice particle is just $0.25 \times D_{\max }$. The capacitance of the ice particle is used to define its growth by diffusion of water vapour (cf. the droplet growth equation).

Also, worthy of note is that the projected area of an ice crystal also has a fractal-like dimension, which for aggregates that are approximately isometric is $\sim 1.33$ (Schmitt and Heymsfield, 2010).

$A\left(D_{\max }\right)=c \times D_{\text {max }}^{d}$

where $A$ is the particle projected area, $D_{\max }$ is the maximum dimension of the particle, $d=\sim 1.33$ and $c$ is unknown. We 
make the reasonable assumption that when there is only one crystal within an ice particle that its area is given by either the area of a circle, with radius equal to the a-axis (in the case of a plate), or an ellipse with semi-minor axis equal to the aaxis and semi-major axis equal to the c-axis (in the case of a column). This allows us to define $c$ in Eq. (8) and therefore the projected area for the aggregate.

Our motivation to be able to define the projected area is that it defines the volume swept-out by the crystal, which is needed to define the collection kernel (Eq. 2). Knowledge of both the projected area and the maximum dimension of the crystal also allows us to define the area ratio, which is the ratio of the projected area to that of a circle with diameter equal to the maximum dimension of the ice particle. The area ratio, $A_{\mathrm{r}}$, is used to calculate accurate fall-speeds of the ice particles, following Heymsfield and Westbrook (2010).

Riming was hardly observed in the CPI images, and was also shown to be only responsible for a very small amount growth within the model; therefore, we switched off growth by riming within the model.

Information specific to each particle bin (i.e. concentration, shape, density) is advected in the vertical; hence, the model includes the effects of size sorting of particles with different terminal fall-speed; the method used for advection is now described below.

\subsubsection{Description of advection schemes within the model}

The growth of liquid or ice in bin microphysical models presents some challenges. There are generally two ways of representing the particle bins within the ACPIM. These are: (i) single moment, where the mass grid stays constant and concentration is advected into smaller or larger bins depending on whether the categories are evaporating or growing; and (ii) double moment where the mass grid is variable (e.g. the hybrid schemes or moving centre schemes of Chen and Lamb, 1994b; Jacobson, 1999). For the single moment scheme we have coded the "quasi-stationary" algorithm for mass transport up and down the bin grid (Jacobson, 1999), which is equivalent to the Kovetz and Olund (1969) binning scheme, which is more widely used in cloud microphysical modelling, and is known to be numerically diffusive. We have also coded a semi-Lagrangian bin-advection scheme based on that described in Bott et al. (1990), which is less diffusive and probably the best that can be done with a single moment bin scheme.

Furthermore within the 1-D column version of ACPIM, each mass bin (liquid and ice) is advected in the vertical with a velocity equal to the vertical wind minus the particles terminal fall-speed. Water vapour and potential temperature, being conserved in dry adiabatic processes are also transported with a velocity equal to the vertical wind. In these simulations we assume a vertical wind speed of zero for all experiments, which is a good assumption, so water vapour and potential temperature were not advected.

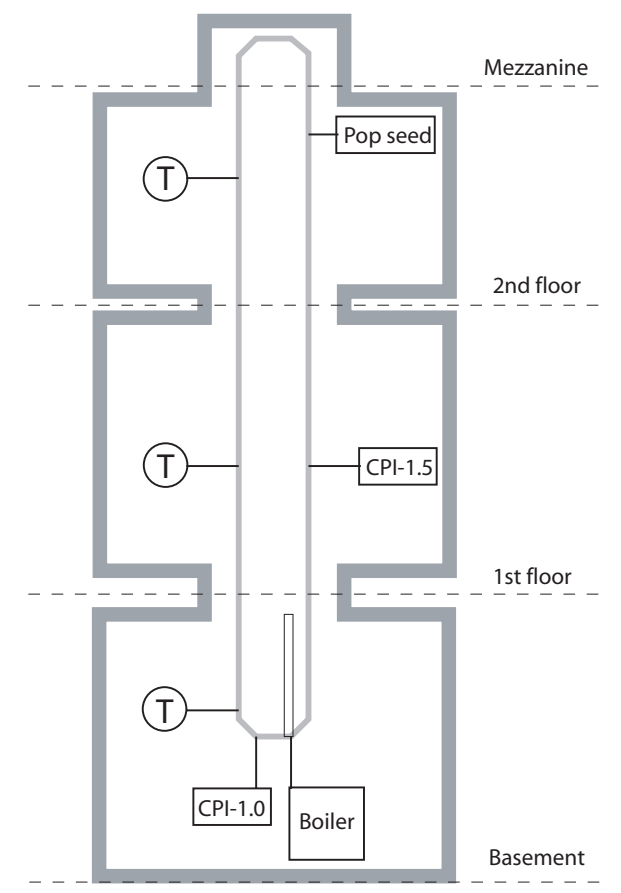

Fig. 1. A schematic of the Manchester Ice Cloud Chamber, which is situated on 3 floors of the Simon building at the University of Manchester. Temperature is measured at three positions within the chamber using two probes at each position; a boiler supplies the chamber with cloud drops and water vapour from the bottom, which rises through the chamber by buoyancy and mixing; two CPI's are used to take images of cloud particles and construct quantitative size distribution information at the base of the chamber and in the middle of the chamber; a "pop seed", which is a compressed airline connected to a solenoid valve that extends into the chamber via a $1 / 4^{\prime \prime}$ pipe, is used to nucleate the ice phase at the top of the chamber, which then grows by vapour diffusion and aggregation as it falls to the bottom of the chamber.

For the single moment representation of the bin grid, high order advection schemes such as the positive definite, mass conserving schemes of Bott $(1989,1992)$ including modifications to the polynomial interpolation required to extend them to 8th order (Costa and Sampaio, 1997) can be used and have been coded within ACPIM. However, for the double moment scheme a different approach must be used for advection; we have developed a scheme based on the hybrid binning scheme described by Chen and Lamb (1994b), which is slightly more expensive than the Bott schemes as it requires an extra prognostic variable per bin to store the average position of the category in the vertical.

We attempted to model processes occurring within the experiment by setting up ACPIM with 40 vertical levels on an Eulerian grid with a resolution of $\Delta z=0.25 \mathrm{~m}$ and a timestep of $\Delta t=1 \mathrm{~s}$. The temperature in these tests was held at a constant $T=-5^{\circ} \mathrm{C}$ for the whole domain, and the relative humidity was held at water saturation throughout the 

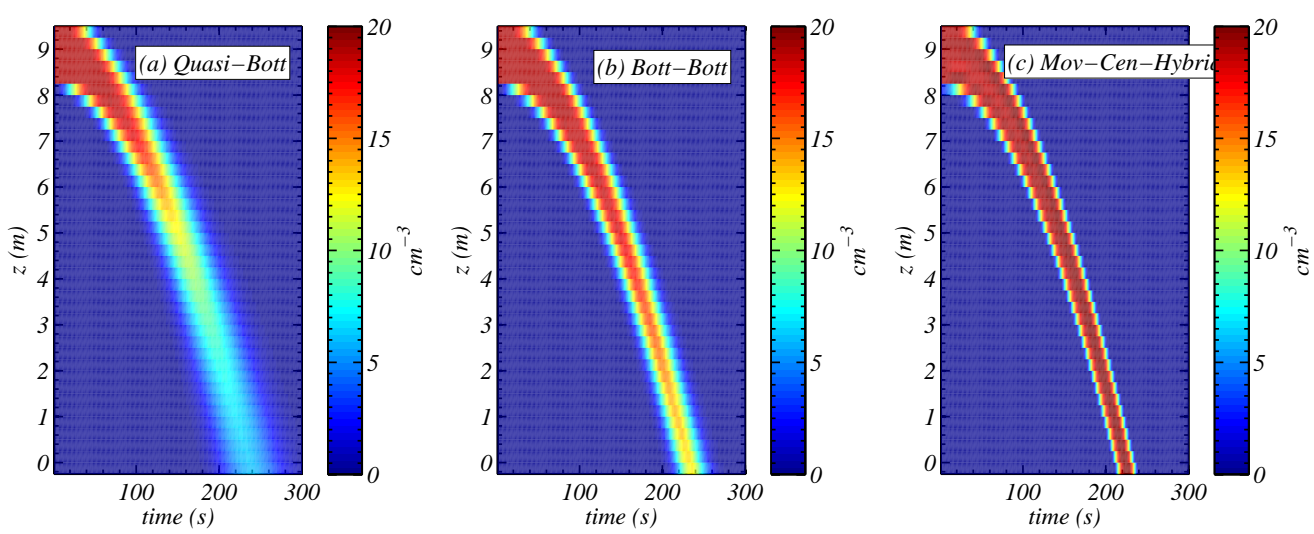

Fig. 2. Shows the evolution of ice crystal concentration for each of the different representations of the model bin-advection and vertical advection. Panel (a) shows the quasi-stationary algorithm together with 8th order Bott advection in the vertical; (b) shows 8th order Bott advection for both bins and vertical advection; and (c) shows the moving centre algorithm together with a two moment advection scheme. It can be seen that scheme (a) artificially reduces the peak concentration by a factor of three; (b) is less diffusive, but still reduces the concentration by a factor of about 1.5 ; (c) maintains the peak in concentration.
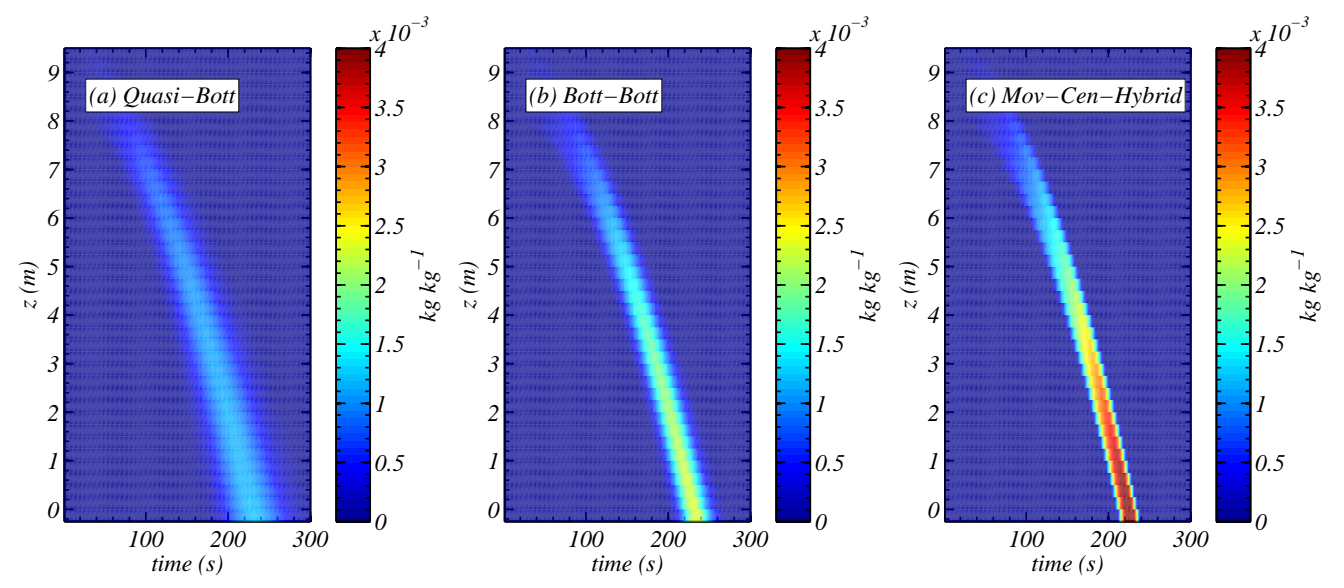

Fig. 3. As Fig. 2, but for ice mass. It can be seen that the peak in mass is significantly affected in the single moment model runs (a) and (b) compared to the double moment scheme (c).

experiment, which was the case in the initial stages of our experiments. Ice crystals in the model are put in the highest $2 \mathrm{~m}$ of the domain instantaneously near the start of the model run to simulate the "pop seed" device at the top of our chamber. We performed this initial test without aggregation switched on to assess whether the models can adequately preserve the peak ice concentration of ice crystals, since this is vital to be able to compare with the experiments. In this model run, because all crystals are growing at water saturation and are not aggregating (so therefore not reducing in number), we should expect that the crystals all fall at the same rate and so the concentration at the start of the model run should be the same as at the end.

We performed three tests with different numerical schemes for bin advection and vertical advection:
1. Using the "quasi-stationary"/Kovetz and Olund scheme for bin-advection in conjunction with the 8th order polynomial, monotone version of the Bott schemes - single moment.

2. Using an 8th order monotone Bott scheme for both advection of size bins and advection in the vertical - single moment.

3. Using the moving centre scheme (Jacobson, 1999) for bin advection and the hybrid two moment scheme Chen and Lamb (1994b) for advection in the vertical - double moment.

Figure 2 shows the results for this test for the ice crystal number concentration field. It can be seen that both single moment schemes are diffusive and artificially reduce the ice crystal number concentration field. This is not desirable for 


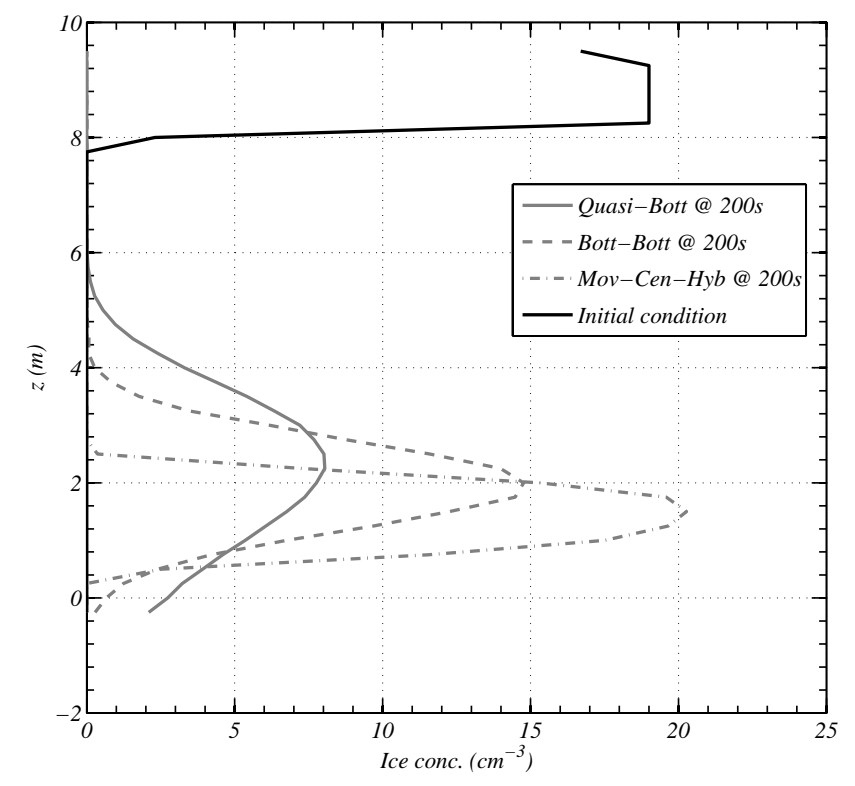

Fig. 4. Shows the initial ice concentration (black solid line) and the ice concentration for each of the model runs. It can be seen that the two single moment schemes are diffusive, while the double moment scheme is not.

interpreting the results. The double moment scheme maintains the peak in ice concentration well. This highlights that for applications to the atmosphere, single moment bin microphysical schemes may suffer from such artefacts and so should be evaluated and improved if necessary. The spreading out in the ice concentration field has a profound effect on the ice mass mixing ratio (as can been seen in Fig. 3). The most diffusive scheme has a peak ice mass mixing ratio of perhaps a factor of 2.5 less than that of the double moment scheme. For processes that are strongly dependent on mass mixing ratio (such as aggregation), this highlights that single moment schemes may not be very useful for model studies of the cloud microphysics. We also show evidence for strong numerical diffusion in the single moment schemes in Fig. 4. The reason for this is because single moment bin schemes always transfer a finite concentration into larger bins, which then grow and fall faster than they should. The single moment vertical advection also leaves a finite amount of ice number concentration in bins that are high up in the cloud, whereas the hybrid two-moment method does not. Note that this problem is not reduced by simply increasing the number of size-bins in the model. Consequently in all further model runs presented in the paper we use the two-moment hybrid method with a moving centre bin scheme - note we also did some model runs using the two-moment hybrid scheme for bin advection and found no difference when compared to the moving centre method for the model set-up described here.

\subsection{Technique applied to determine the aggregation efficiency}

In order to determine the aggregation efficiency we apply the following technique. We used the number concentration data from the two CPI's to compare with a model simulation of the experiments, that had a set value of $E_{\text {agg }}$ used as input. We calculated the "goodness-of-fit" of the model to the observations by calculating the difference in ice concentration at the two peaks on both data sets, squaring this difference and then adding them together:

$$
\left(N_{\text {model,top }}-N_{\text {meas, top }}\right)^{2}+\left(N_{\text {model, bot }}-N_{\text {meas, bot }}\right)^{2}
$$

where $N_{\text {model,top }}$ and $N_{\text {model,bot }}$ are the modelled ice particle number concentration at the top and bottom positions in the chamber, averaged over $\sim 30 \mathrm{~s}$, and $N_{\text {meas,top }}$ and $N_{\text {meas, bot }}$ are the corresponding measured values of the ice particle number concentration at the same locations. A low value of this statistic means that the model and observations are in good agreement and vice-versa. We did this for many different values of $E_{\text {agg }}$ and generated a plot of the goodness-of-fit vs. $E_{\text {agg }}$ (Fig. 5 b shows a schematic of how this may look). If we are able to locate a minimum in this graph then it denotes the best estimate of $E_{\text {agg }}$ for that particular experiment. We then generated a large number of random values of $E_{\text {agg }}$ and used the relationship in Fig. 5b to derive the distribution of goodness-of-fit parameters for a random sample of $E_{\text {agg values and assigned a significance level below which }}$ the value of the goodness-of-fit was significantly worse than those above the level of significance (see Fig. 5c). The value of the goodness-of-fit that this occurs at is denoted the critical value of the goodness-of-fit and this can be remapped to find the confidence interval for $E_{\text {agg }}$ (see Fig. 5d). In this way we can derive maximum likelihood estimates and error bars for $E_{\text {agg }}$ for all experiments.

Note that we found the ice concentration in the model formed in definite pulses, between the top and the bottom locations, with no ice after the main concentration pulse had passed, while the observations from the CPI showed similar initial pulses, after which the concentration remained reasonably high for a period of time (this highlighted in Fig. 5a). The reasons for this are that: (i) as for all chambers, there is a temperature gradient near the top of the chamber, so the crystals right at the top do not grow as fast as the crystals that are lower down in the chamber; and (ii) the leading edge of the pulse of ice crystals falls through the cloud and grows at water saturation, but depletes some of the water vapour, so that just higher than the leading edge of the pulse ice crystals grow at a lower humidity. We attempted to model the chamber with interactive water vapour and cloud simulate this effect to a degree, but we found that less errors were introduced by growing the ice crystals at water saturation and only comparing the leading edge of the observed ice concentration pulse with the modelled pulse. The differences in the 


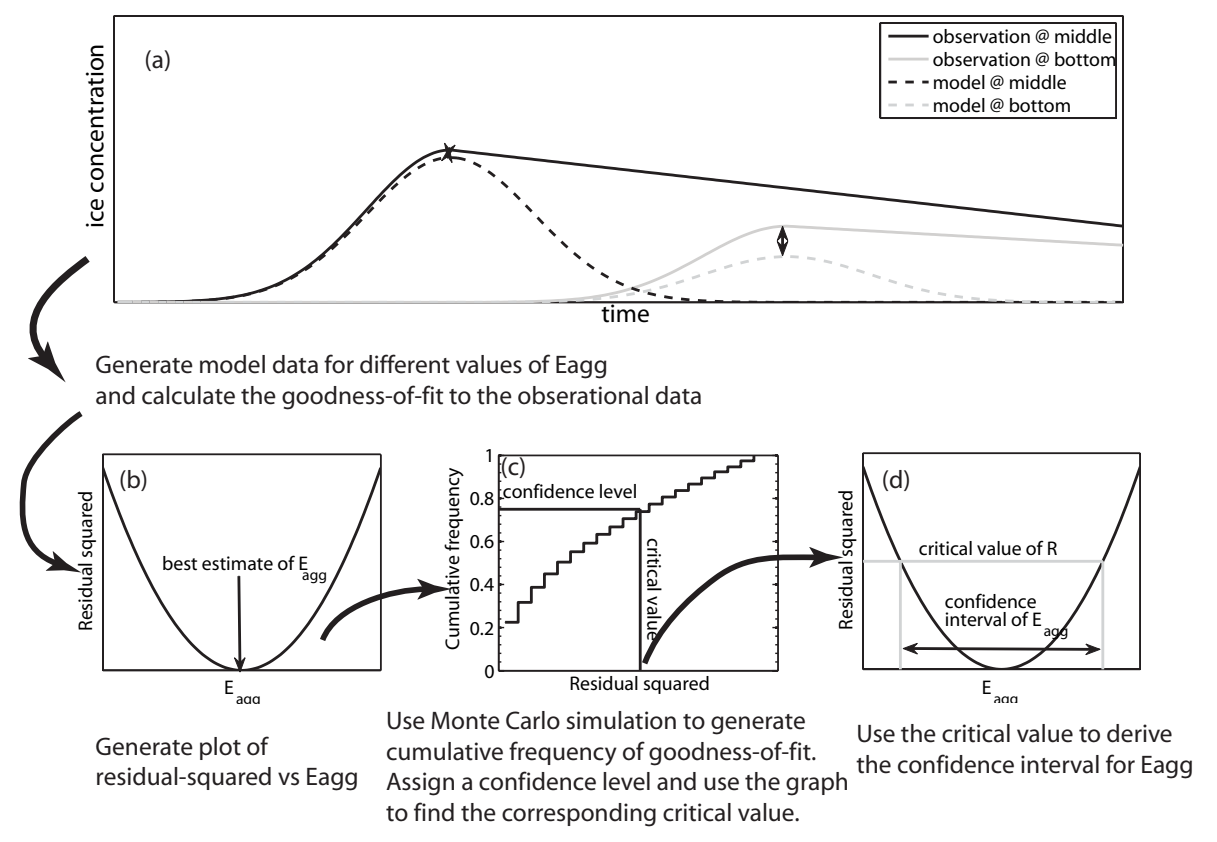

Fig. 5. A schematic of the technique used to find the maximum likelihood estimate and confidence interval of the aggregation efficiency for each experiment. Panel (a) shows a schematic of the observation of ice crystal number at the middle and at the bottom of the chamber, plus the modelled ice concentration for the same positions within a model simulation with an guess for the $E_{\text {agg }}$ parameter. The "goodness-of-fit" is calculated, which is the sum of the residual differences squared for both observation levels. This is done for different values of the $E_{\text {agg }}$ parameter as input into the model, so that a graph of the goodness-of-fit vs. $E_{\text {agg }}$ can be produced (b); the minimum value of the goodnessof-fit on this graph is the best estimate for $E_{\text {agg }}$. Monte Carlo simulation is then used to generate the cumulative fraction of goodness-of-fits (c) and then a significant level for the error bar is assigned (25\%) to find the critical value of the goodness-of-fit above which the observation

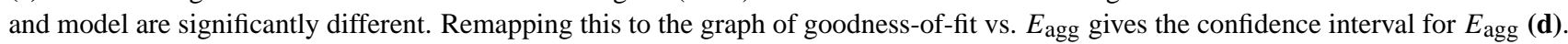

time between the top pulse and the bottom pulse of ice particles were in good agreement between model and data, which suggests that the fall-speed of the ice particles was accurately modelled by using ACPIM.

\section{Results}

In this section we describe the results from the experiments (Sect. 4.1); from the model (Sect. 4.2) and some further analysis (Sect. 4.3) that was required to derive the aggregation efficiency vs. temperature relationship.

\subsection{Experimental results}

The CPI images taken during the experiments are shown in Figs. 6 and 7. Figure 6 shows the images taken in the middle of the chamber and Fig. 7 shows the images taken at the bottom of the chamber. At $-5^{\circ} \mathrm{C}$ we see that the habit type is columnar, which is in agreement with previous observations of habits of vapour grown ice crystals. This changes over to planar crystals at $-10^{\circ} \mathrm{C},-15^{\circ} \mathrm{C}$ and $-20^{\circ} \mathrm{C}$, again in agreement with previous observations of the habits of vapour grown ice crystals. However, we also observed planar crystal growth at $-25^{\circ} \mathrm{C}$, whereas early observations of ice crys- tal growth using static diffusion chambers have documented columnar crystals at this temperature. It is noted that previous findings of ice crystals in free-fall, growing under conditions of water saturation (e.g. Fig. 17 in aufm Kampe et al., 1951) and indeed the latest results by Bailey and Hallett (2009) also show planar growth in this temperature range. The reason for this may be that the transition to columns occurs over a very small temperature interval around $-25^{\circ} \mathrm{C}$, or may be due to the effects of the nucleating substance being used in the early studies. At $-30^{\circ} \mathrm{C}$ we saw plate polycrystals, which is in agreement with results from diffusion chambers (Bailey and Hallett, 2004).

The concentrations measured with both CPIs are shown in Fig. 8, showing the concentrations measured at the middle of the chamber always exceed those measured at the bottom, which shows that the ice crystal concentration has decreased during the descent to the bottom of the chamber. This is to be expected as most of the aggregation occurred between the middle and the bottom of the chamber, as is evident from the images of ice particles in Figs. 6 and 7. Repeat experiments are shown as dashed lines on the graph and in general the experiments show good repeatability. 


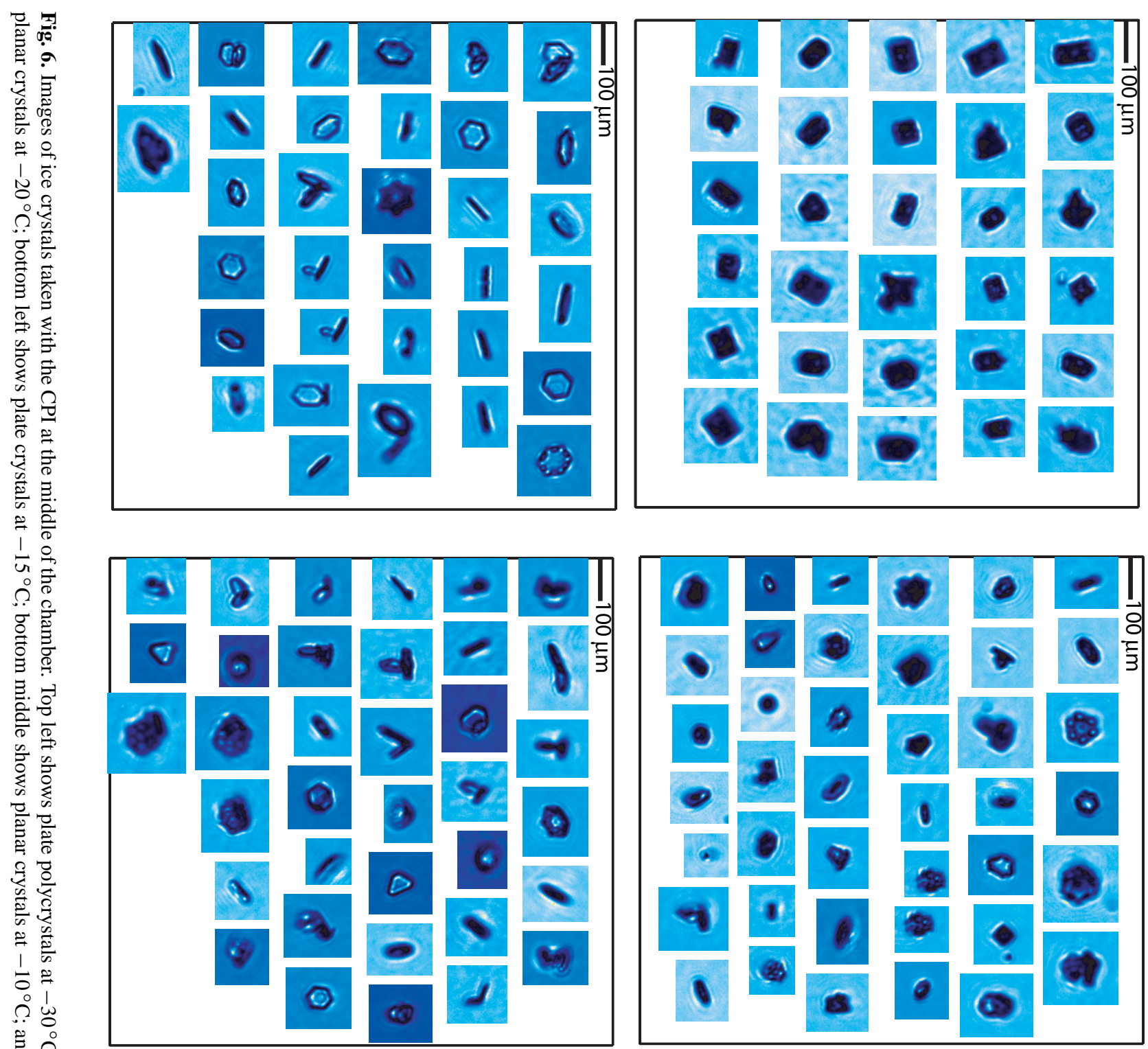

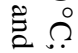

용
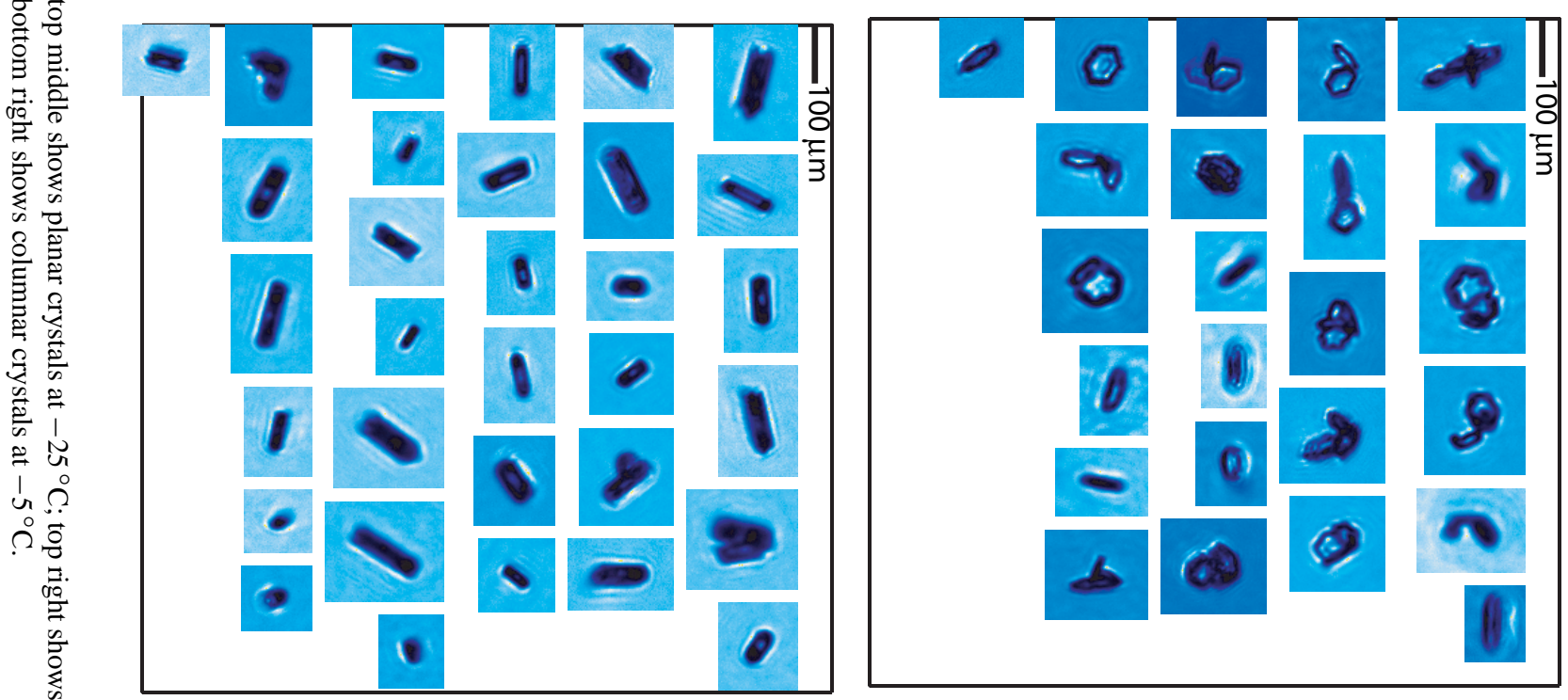

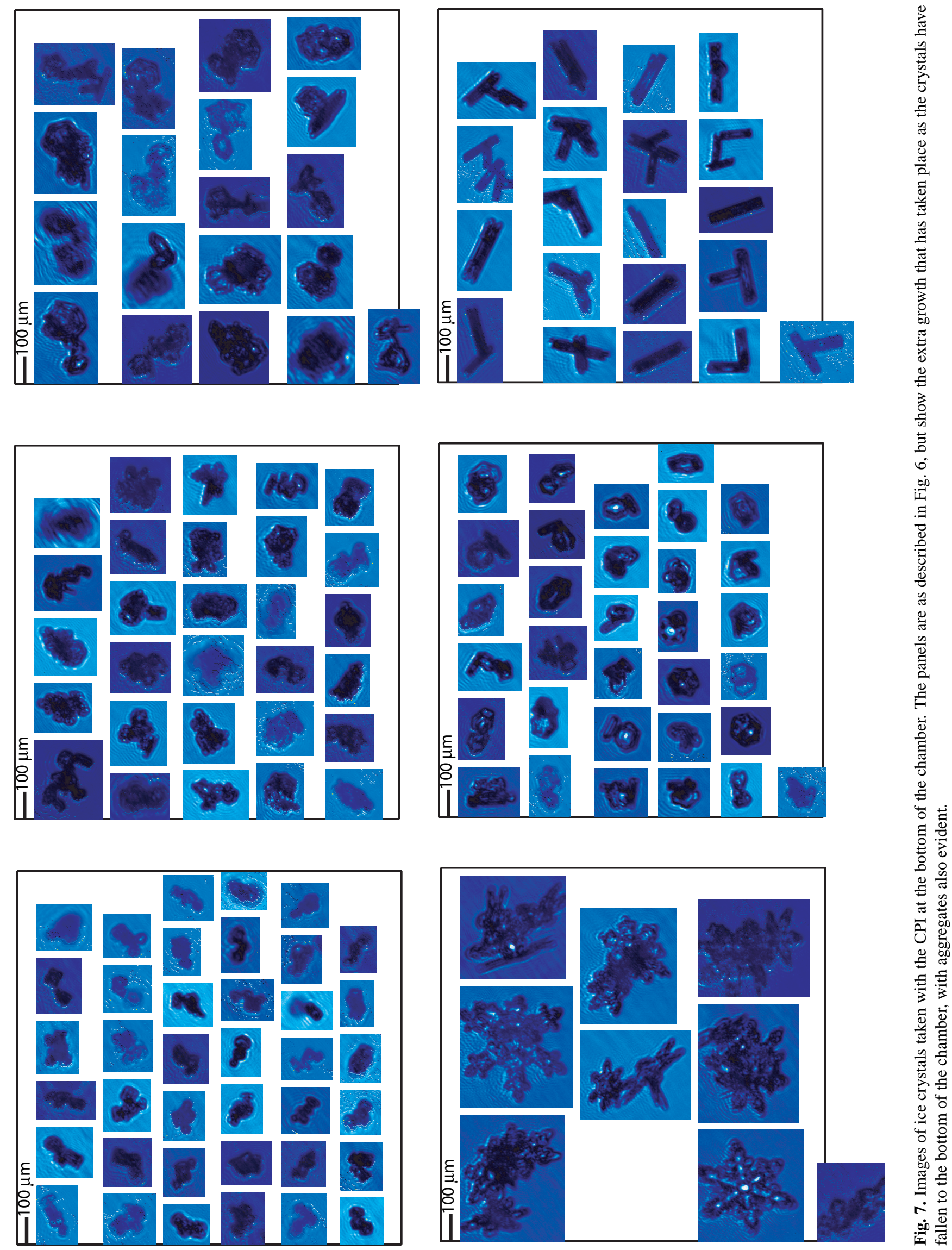
Table 1. Number concentrations of ice crystals nucleated at the top of the chamber by the "pop seed" and used as input to the model simulations.

\begin{tabular}{lrrrrrr}
\hline Temperature $\left({ }^{\circ} \mathrm{C}\right)$ & -5 & -10 & -15 & -20 & -25 & -30 \\
Initial ice crystal concentration $\left(\mathrm{cm}^{-3}\right)$ & 19.0 & 22.5 & 18.5 & 29.0 & 35.5 & 28.0 \\
\hline
\end{tabular}
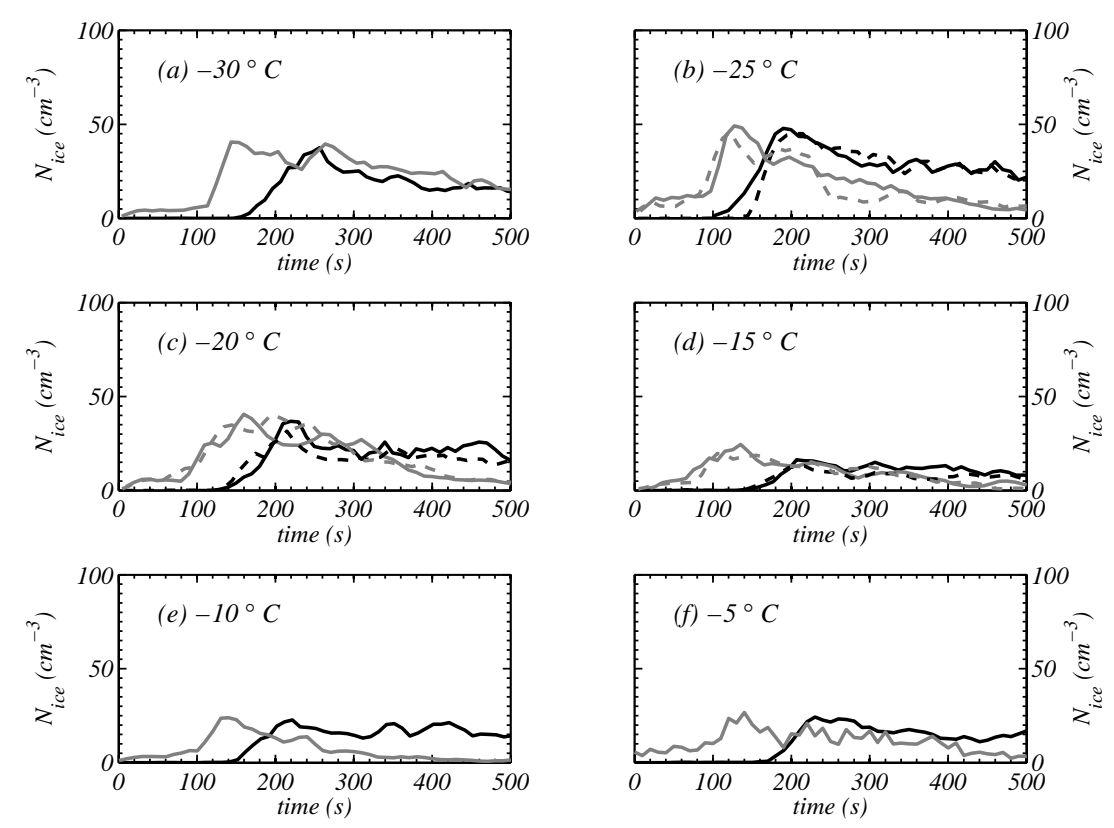

Fig. 8. Shows the concentrations measured with the CPI for the different experiments. Solid grey lines are measurements at the middle of the chamber; solid black lines are measurements at the base of the chamber. Dashed lines are repeat experiments, which show some statistical variability, but in general good agreement. Panel (a) is the experiment at $-30^{\circ} \mathrm{C}$; (b) $-25^{\circ} \mathrm{C}$; (c) $-20^{\circ} \mathrm{C}$; (d) $-15^{\circ} \mathrm{C}$; (e) $-10^{\circ} \mathrm{C}$; and (f) $-5^{\circ} \mathrm{C}$.

In order to assess how the shape of the distribution changes with distance fallen we fitted exponential spectra of the form:

$\frac{d N}{d D}=n_{0} \exp (-\lambda D)$

where $N$ is the number of ice crystals, $D$ the maximum length of the ice crystals, $n_{0}$ the intercept parameter for the exponential distribution and $\lambda$ the slope of the distribution in $\log$-linear space. Details of how this was done are given in the Appendix.

An example of a measured size distributions from the CPI's as well as best fits, using the exponential function in Eq. (10), from an experiment at $-15^{\circ} \mathrm{C}$ is shown in Fig. 9. In this experiment the initial crystal sizes were $<100 \mu \mathrm{m}$, but as they fell to the bottom of the chamber grew to sizes $<\sim 500 \mu \mathrm{m}$.

Figure 10 shows the slope parameter derived from both CPI's for all experiments. An interpretation of $\lambda$ is that high values are associated with a narrow size distribution and low values are associated with a broad distribution. Figure 10 shows that for all experiments the distributions get broader towards the bottom of the chamber. We initially thought of using this change in $\lambda$ with height to quantify the aggregation rate in a manner similar to that described in Passarelli (1978); Mitchell (1988); however, uncertainties in parameter inputs required for this model, such as the constants in the mass-dimension and velocity-dimension relations for the ice crystals, often led to overestimates of $E_{\text {agg }}$, sometimes giving values in excess of $E_{\mathrm{agg}}=1$ and so we opted to use the more complex, but realistic, bin-microphysics method.

\subsection{Model results}

In order to generate model data to compare with the observations we ran the model as described in Sect. 3.1.2, using the double moment representation of the bin structure, for the 6 different temperatures investigated in this study $(T=-5$, $-10,-15,-20,-25$ and $\left.-30^{\circ} \mathrm{C}\right)$. Fourteen different values of the aggregation efficiency were run so that the values that best fitted the data could be determined later; the values of $E_{\text {agg }}$ used were: $E_{\text {agg }}=0.000,0.010,0.025,0.050$, $0.0750 .100,0.150,0.200,0.300,0.400,0.500,0.600,0.750$ and 1.000. In the first instance this made a grand total of $6 \times 14=84$ model runs. Note that there was very little (if 


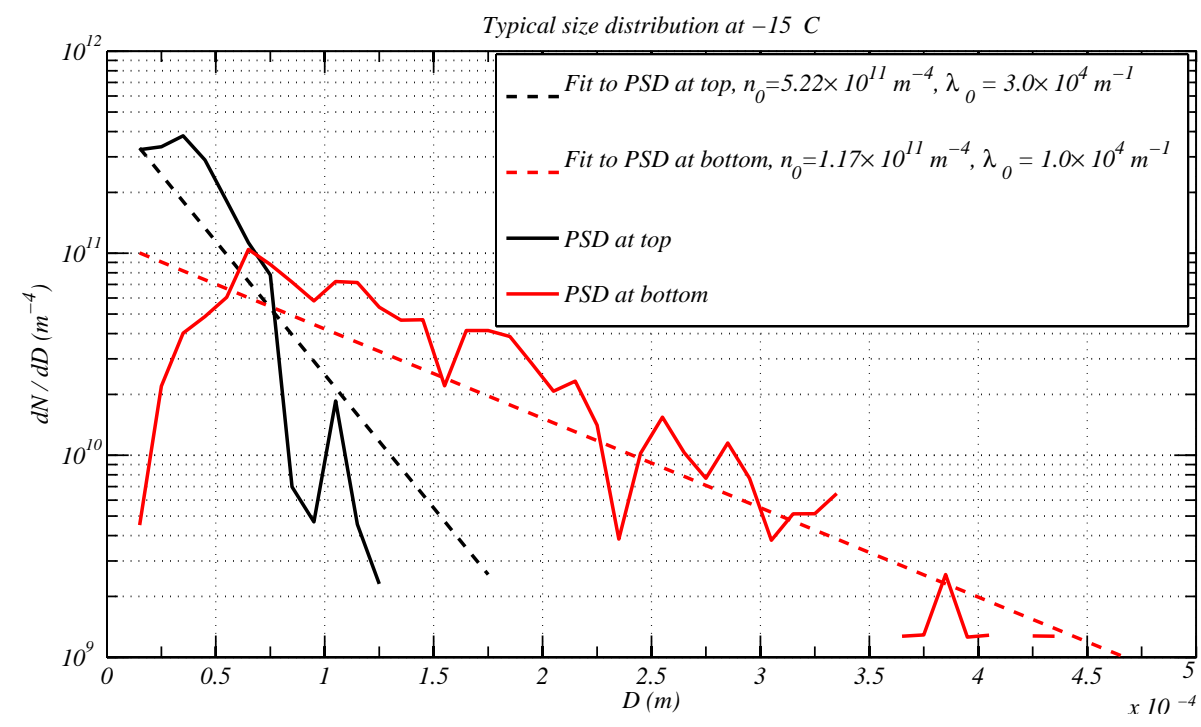

Fig. 9. An example of the ice crystal size distributions measured at the two levels in the chamber with best fits to exponential functions.
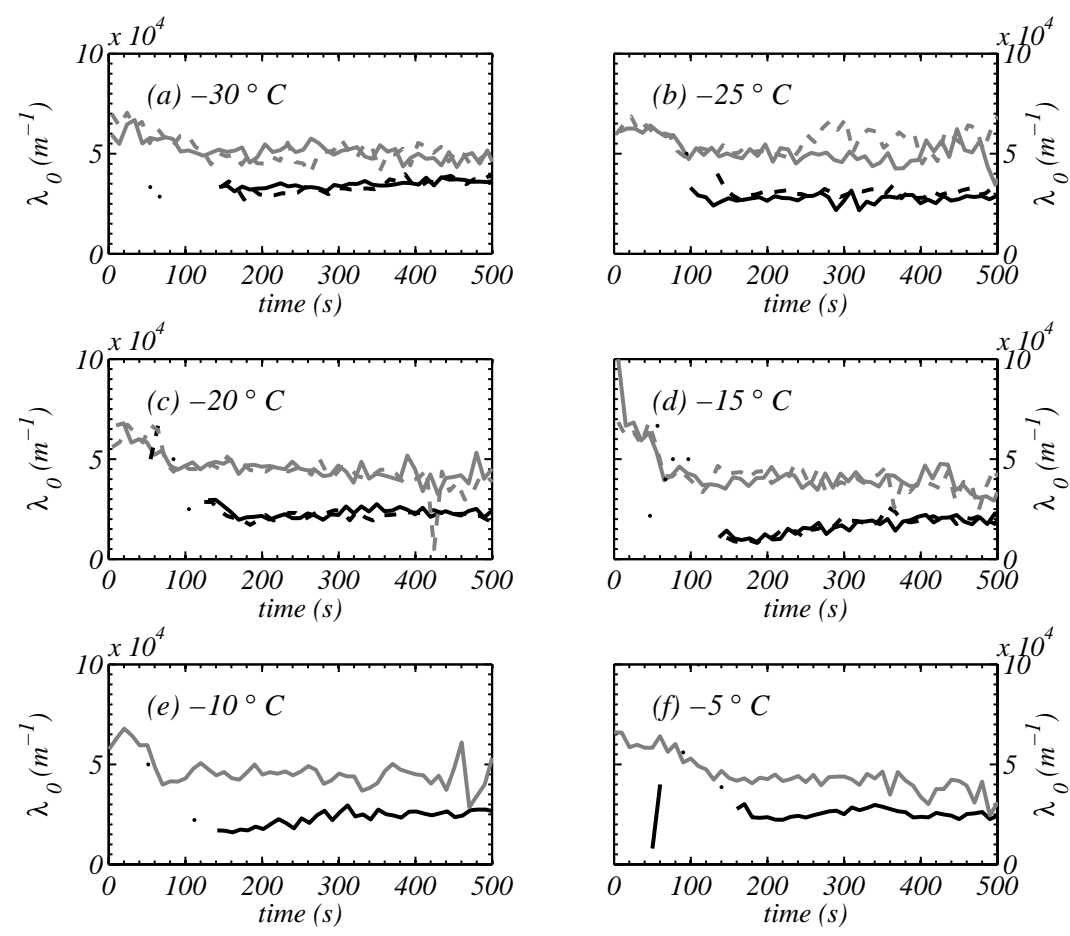

Fig. 10. Shows the slope of the distribution measured with the CPI for the different experiments. Solid grey lines are measurements at the middle of the chamber; solid black lines are measurements at the base of the chamber. Dashed lines are repeat experiments, which show some statistical variability, but in general good agreement. Panels are as in Fig. 8, but the slope is plotted instead of the concentration.

any) evidence of aggregation in the images taken in the middle of the chamber (Fig. 6), so the concentration measured as the ice crystal concentration pulse moved past the first probe was taken to be the initial ice concentration nucleated by the "pop seed" at the top of the chamber; this initial concentration used in each of the experiments is shown in Table 1.
Figure 11 shows an example of the output from ACPIM for two runs at $-15^{\circ} \mathrm{C}$ where in one run the aggregation efficiency was set to zero and in the other run it was set to unity. It can be seen that in the case with no aggregation the ice crystal concentration stays the same as it descends to the bottom of the domain (Fig. 11a) and this results in very high 

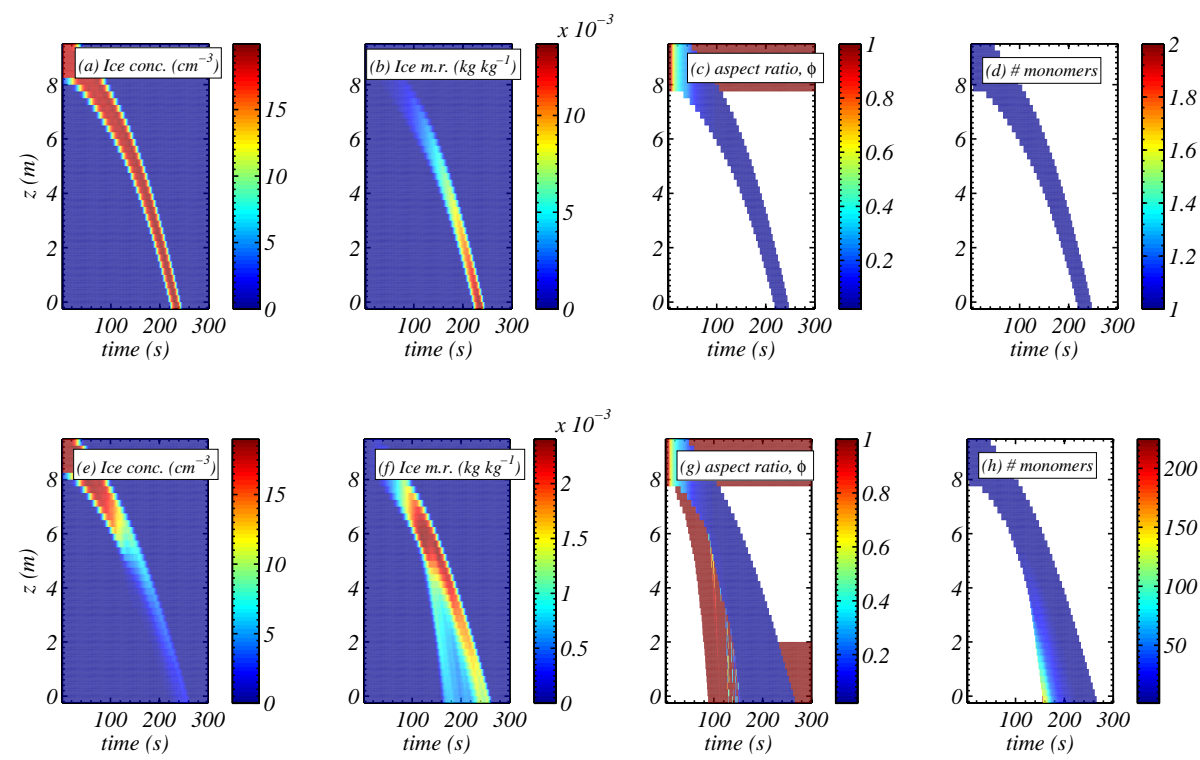

Fig. 11. Model run with $E_{\text {agg }}$ set to zero (top plots) and $E_{\text {agg }}$ set to unity (bottom plots).

Table 2. Ice crystal aspect ratio observed with the CPI (approx.) and that modelled using the standard inherent growth ratio and the modified inherent growth ratio (see text for details). The modelled aspect ratio, $\phi$ is given as the first number in the column and the inherent growth ratio, $\Gamma(T)$ is given as the second number in brackets.

\begin{tabular}{llll}
\hline$T\left({ }^{\circ} \mathrm{C}\right)$ & Observed aspect ratio, $\phi=\frac{c}{a}$ & Standard $\Gamma(T)$ and $\phi=\frac{c}{a}$ & Modified $\Gamma(T)$ and $\phi=\frac{c}{a}$ \\
\hline-5 & $\sim 5.5$ & $1.40(4.50)$ & - \\
-10 & $\sim 1 / 8$ & $0.90(0.55)$ & $0.60(1 / 8)$ \\
-15 & $\sim 1 / 50-1 / 30$ & $0.45(1 / 50)$ & - \\
-20 & $\sim 1 / 20$ & $0.75(0.50)$ & $0.55(1 / 15)$ \\
-25 & $\sim 1 / 20$ & $1.60(5.00)$ & $0.55(1 / 10)$ \\
-30 & $\sim 1 / 5$ & $1.20(2.00)$ & $0.70(1 / 3)$ \\
\hline
\end{tabular}

mass mixing ratios of ice, in excess of $10 \times 10^{-3} \mathrm{~kg} \mathrm{~kg}^{-1}$ (Fig. 11b). It can also be seen that it takes in excess of $200 \mathrm{~s}$ for the first ice to be present at the bottom of the domain. In the case with an aggregation efficiency of unity it can be seen that the ice concentration decreases rapidly when the ice falls a distance of around $3 \mathrm{~m}$ from the top of the model domain (Fig. 11e), and the peak ice mass is much lower, but spread out in height, compared to the case with zero aggregation (Fig. 11f). Ice reaches the bottom of the domain much sooner in the case with aggregation (at approximately $150 \mathrm{~s}$, compared to $210 \mathrm{~s}$ without aggregation) and it can be seen that the ice with the most monomers (i.e. the most aggregated ice particles) are the ones that reach the bottom of the domain first, Fig. $11 \mathrm{~h}$ ). Note that in both runs shown, at $-15^{\circ} \mathrm{C}$, the crystal habit has an aspect ratio of around $1 / 50$, which denotes thin planar habits/or dendrites. This aspect ratio was calculated due to the low value of the inherent growth ratio, suggested by Chen and Lamb (1994a), that was used at this temperature, $\Gamma(-15)=0.45$.
The first set of 48 runs were scrutinised for their ability to reproduce the ice crystal habits that were observed with the CPI. It was found that the run at -5 produced crystals habits that had very similar aspect ratios to those observed with the $\mathrm{CPI}$ and the run at -15 produced crystals that had low aspect ratios, which due to experimental uncertainty could be estimated to be between $1 / 50$ and $1 / 30^{1}$. Initially we decided that the modelled value of $1 / 50$ was close enough to the measured aspect ratio of the crystals, but later decided that it was likely too low (see Sect. 4.3)

The runs at $-10,-20,-25$ and $-30{ }^{\circ} \mathrm{C}$ did not produce ice crystals with the measured aspect ratio. This had the impact of the two pulses in ice concentration (at the middle and at the bottom of the chamber) not lining up well in time with the observations - the reason for this was that the modelled fall-speeds were not correct, as the habits were completely

\footnotetext{
${ }^{1}$ The measured aspect ratio was determined from the CPI images, which are 2-D and sampled at random orientations. The potential for errors in estimating the aspect ratio is noted.
} 
wrong. Consequently we altered the inherent growth ratio, $\Gamma(T)$, in the model so that the habits produced by the model were in closer agreement to those observed and re-ran the model for the experiments at $-10,-20,-25$ and $-30^{\circ} \mathrm{C}$.

It is intriguing why the habits observed did not match the modelled habits, since the inherent growth ratio was taken from Chen and Lamb (1994a), which is also based on laboratory data by several authors. A possible explanation is that ice crystal habit is influenced by the nucleation method, which has been observed by Bacon et al. (2003) and habits reported in previous literature arise due to a different nucleation method than ours; another possible explanation is that the ice crystals aspect ratios that the inherent growth ratio is based on were grown in diffusion chambers, whereas ours were in free-fall, which could have some impact on the crystal habit because of possible effects of ventilation on their growth. It should be noted that similar aspect ratios were observed between the mid-level CPI and the low-level CPI so we do not expect that aggregation itself is affecting the aspect ratio of the ice crystals.

Table 2 shows the observed ice crystal aspect ratios, that we roughly estimated from the CPI images, as well as those modelled by the standard inherent growth ratio, $\Gamma(T)$, (from Chen and Lamb, 1994a) and those modelled by the modified inherent growth ratio (based on our estimates of the measured aspect ratio). It shows that changing the inherent growth ratio resulted in better agreement between the modelled and observed aspect ratio. We could have spent more time trying to tune this, however, it was deemed that modelled inherent growth ratio was close enough to that measured so as not to affect the results too much, given the uncertainties that also exist in determining the ice crystal concentration, observed aspect ratio and other experimental errors.

\subsection{Further analysis}

To analyse the results we used the method described in Sect. 3.2; that is we calculated the difference between the modelled ice concentration at the two observation levels, squared these differences and added them together. We did this for all values of the aggregation efficiency that we used to run the model and therefore created the residual vs. $E_{\text {agg }}$ plots shown in Fig. 12. All of the plots in Fig. 12 have a minimum at some point in the interval $0<E_{\text {agg }} \leq 1$, meaning that our best guess is that the aggregation efficiency is greater than 0 at all temperatures in the interval $-30 \leq T \leq-5^{\circ} \mathrm{C}$.

The maximum likelihood estimate or best guess of the aggregation efficiency was determined by finding the value of $E_{\text {agg }}$ that minimises the residual for that experiment, which is fairly trivial to read from the plots in Fig. 12. This represents the value of the aggregation efficiency that gives the best agreement between model and data and hence, our best estimate of the aggregation efficiency. Since we assume that possible values for the aggregation efficiency lie in the interval $0<E_{\mathrm{agg}} \leq 1$ we can estimate a confidence limit outside of which we say that the chosen value of $E_{\text {agg }}$ is unrealistic. The confidence interval for $E_{\text {agg }}$ was determined in the following way. The residual plots were used to generate cumulative histograms of the residuals using Monte Carlo simulation of the aggregation efficiency, $E_{\text {agg. }}$. That is we treated $E_{\text {agg }}$ as a random variable and generated $10^{6}$ values lying between 0 and 1 using a random number generator. The functional form of the residual plot was used to transform the $10^{6}$ random numbers into a residual by using 1-D interpolation of the residual vs. $E_{\text {agg }}$ relationship (in Fig. 12 ) and then cumulative histograms were generated from the resulting residuals. The 25th and 75th percentile were located on the cumulative histograms of the residuals and the value of the residual that corresponded to this was found (again by 1-D interpolation). Once this value was found we defined the 25th percentile for $E_{\text {agg }}$ as the minimum value of $E_{\text {agg }}$ in all Monte Carlo realisations that resulted in a residual equal to the 25 th percentile; conversely to find the 75th percentile for $E_{\text {agg }}$ we found the maximum value of $E_{\text {agg }}$ that resulted in a residual equal to the 75th percentile ${ }^{2}$. These estimates, along with the data of Hosler and Halgren are shown in Fig. 14a.

\section{Comparison of number of monomers per aggregate}

In order to further validate our approach we compared the measured number of monomers per aggregate in different size ranges, deduced from visual inspection of the CPI imagery, with that predicted by the model when using the value of $E_{\text {agg }}$ that best matches the data - i.e. the MLE values shown in Fig. 14a.

To deduce the number of monomer ice crystals measured in different size ranges we first visually inspected a sample of 100 CPI images in each $50 \mathrm{~s}$ interval of the experiments for particles that have a maximum dimension, $D_{\max }$ (as measured by the CPI) in the size-intervals $100 \leq D_{\max }<200 \mu \mathrm{m}$; $200 \leq D_{\max }<300 \mu \mathrm{m}$ and $300 \leq D_{\max }<400 \mu \mathrm{m}$. Examples CPI images of ice particles with different numbers of ice crystal monomers in them are shown in Fig. 15.

We then compared this number to the equivalent modelled number of monomer ice crystals in the same size bins. The results of this comparison are shown in Fig. 16.

It can be seen that in general there is reasonable agreement for all temperatures except at $-15^{\circ} \mathrm{C}$ between model and data. At $-15^{\circ} \mathrm{C}$, when the low value of the inherent growth ratio was used (i.e. $\Gamma(-15)=0.45$ ) we find that the number of monomers in each size range is $\sim 1$. The reason for this is that the ice crystals grow to very large maximum dimensions when they have low aspect ratios (1/50) and so it is the unaggregated particles that are present in these size

\footnotetext{
${ }^{2}$ Note that we could have attempted to calculate the error bars for $E_{\text {agg }}$ by finding the interval over which the area under the residual$E_{\text {agg }}$ curve is some specified fraction of the total area; however this would require iteration to find the interval, which is more computationally expensive.
} 

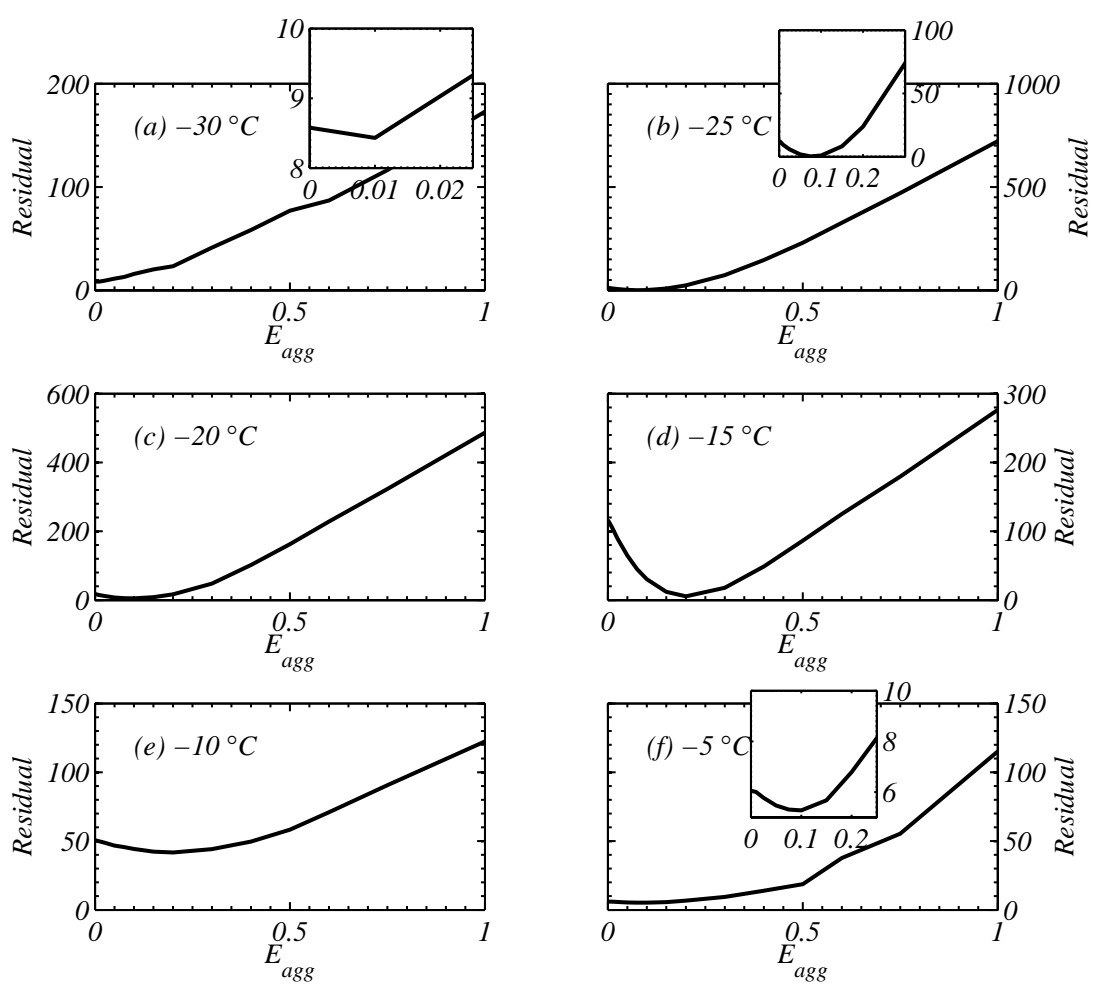

Fig. 12. Plots of the residual differences between the model and observations for the different experiments. Note the value of $E_{\text {agg }}$ where the residual is a minimum denotes the value of $E_{\text {agg }}$ that best matches the data or the maximum likelihood estimate. Inset are expanded plots for the cases where the minima are not clearly visible.

ranges. This prompted us to increase the inherent growth ratio at $-15^{\circ} \mathrm{C}$ to 0.55 , which produced particle aspect ratios of $\sim 1 / 30$, which is still in reasonable agreement to the measured aspect ratio (see Sect. 4.3). Increasing the inherent growth ratio, and therefore crystal aspect ratio has the effect of increasing our estimate of the aggregation efficiency at $-15^{\circ} \mathrm{C}$ by a factor of 3 (see Fig. 13 and Fig. 14b), since the ice crystal projected area is reduced so $E_{\text {agg }}$ must by increased to compensate in the hydrodynamic kernel (Eq. 2). Furthermore when this modified inherent growth ratio and aggregation efficiency is used at $-15^{\circ} \mathrm{C}$ we see much better agreement in the average number of monomers per aggregate (Fig. 16).

We therefore suggest that Fig. 14b provides our best set of estimates for the aggregation efficiency in our experiments.

\section{Discussion}

At temperatures other than $-15^{\circ} \mathrm{C}$ the results of this study are in general agreement with those of Hosler and Halgren (1960), who showed evidence of a maximum in aggregation efficiency for crystals grown at $-15^{\circ} \mathrm{C}$ of about 0.1 to 0.2 . We suggest that the reason we observed a much higher aggregation efficiency at $-15^{\circ} \mathrm{C}$ is because the ice crystals in our experiments were large and complex, while in Hosler and

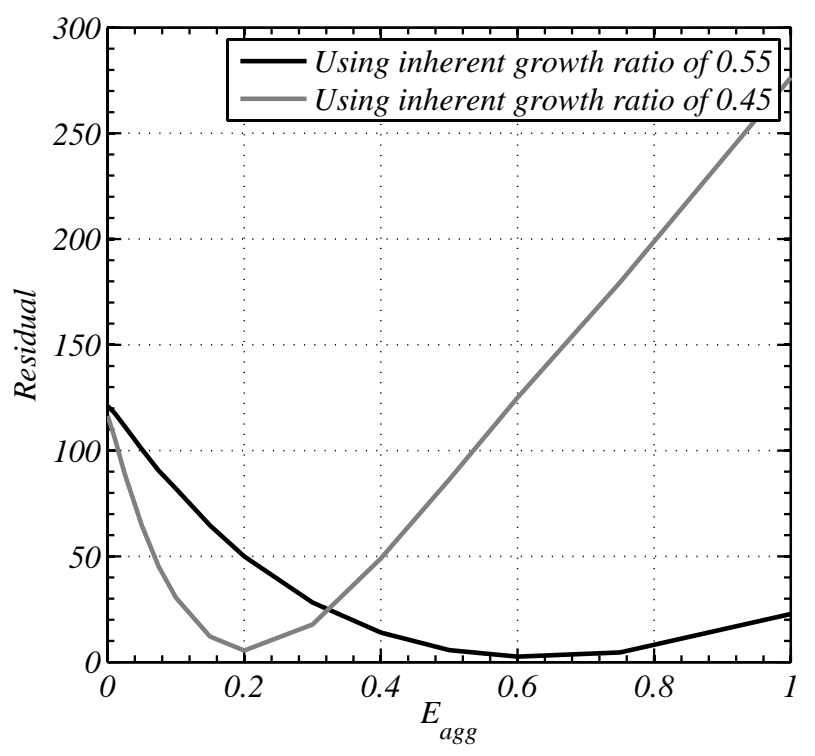

Fig. 13. As in Fig. 12, but for the experiment at $-15^{\circ} \mathrm{C}$. The two curves are the residual plotted for when $\Gamma(-15)=0.55$ and $\Gamma(-15)=0.45$. Note that the curve for $\Gamma(-15)=0.55$ has a minimum at $E_{\text {agg }} \cong 0.6$, which is much higher than the previous estimate. Also note that the value of residual at the minimum is less than that for $\Gamma(-15)=0.45$, so this solution better matches the data. 

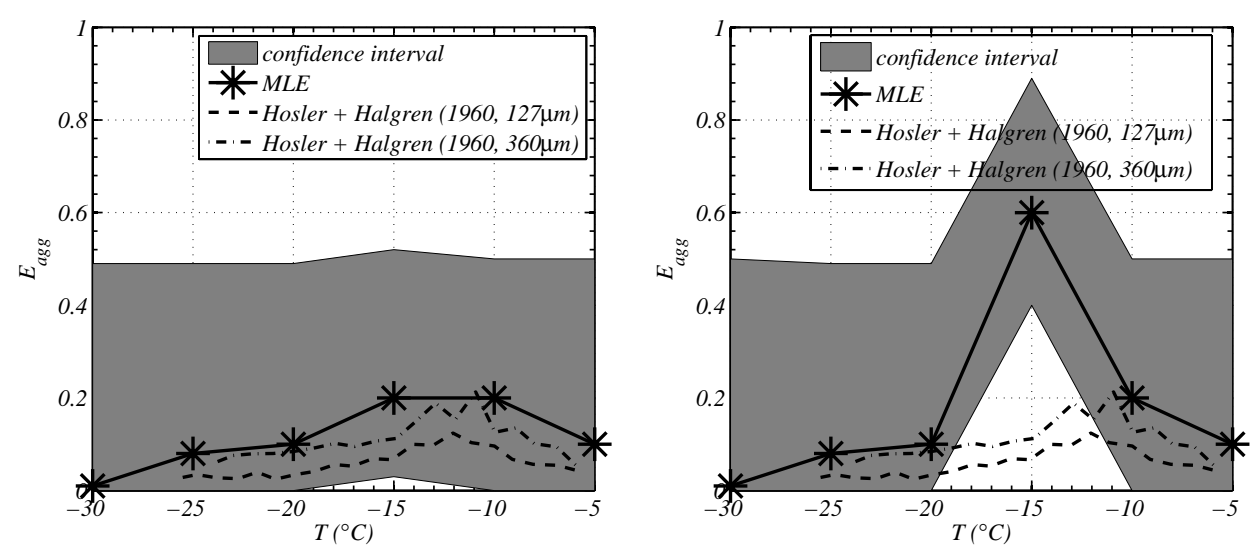

Fig. 14. Our estimates (MLE - maximum likelihood estimate) of the aggregation efficiency vs. temperature, with the results of Hosler and Halgren also shown. Panel (a) shows our estimate using a low value of the inherent growth ratio; (b) shows our estimate when using a higher value of the inherent growth ratio, which gives better agreement with the number of monomers in each size range (Fig. 16).

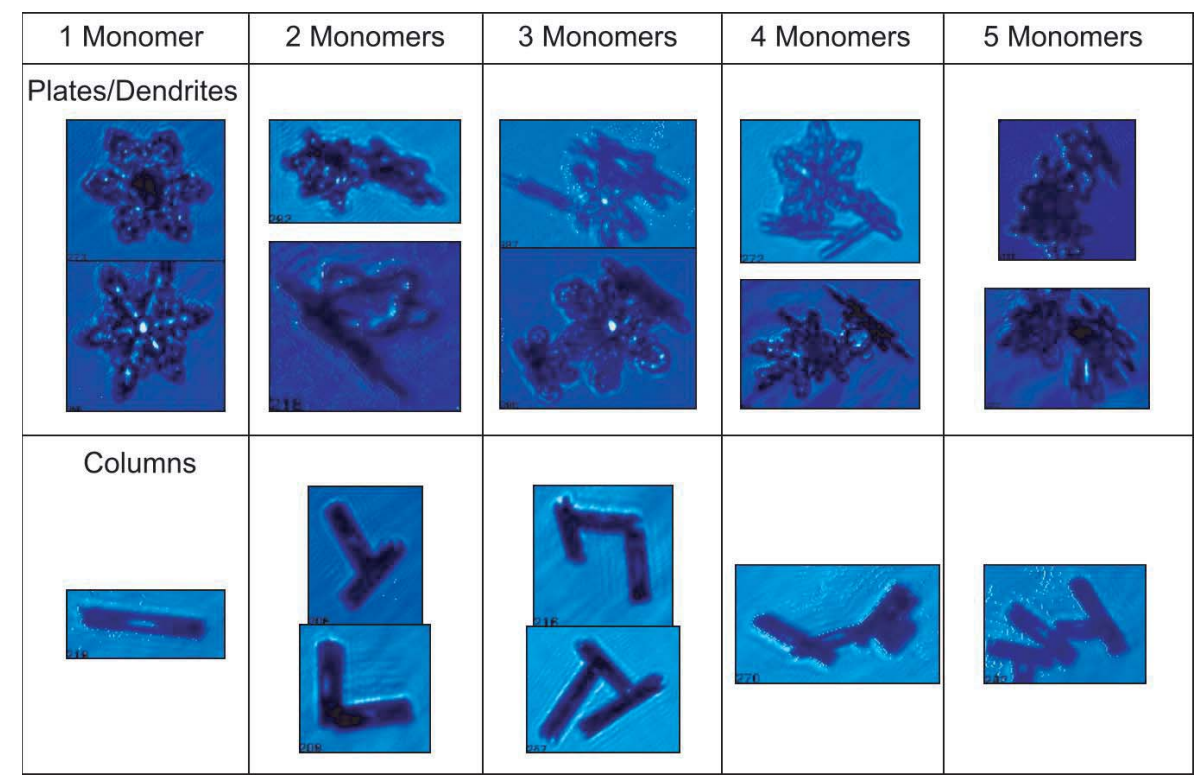

Fig. 15. Some examples of aggregated ice crystals of either planar or columnar habit, with 1, 2, 3, 4 and 5 monomers.

Halgren's study they were small $(\sim 7-18 \mu \mathrm{m})$. We suggest that interlocking of the branches on the ice crystals is very important to the aggregation process and can enhance aggregation efficiencies by at least a factor of 3 .

We also note that crystals grown at both -20 and $-25^{\circ} \mathrm{C}$ our experiments indicate aggregation efficiencies $\sim 0.1$, which are higher than the study of Hosler and Halgren (1960). We suggest that a possible reason for this discrepancy is that in the study of Hosler and Halgren (1960) the ice crystals were aspirated passed a large ice target at an airspeed equal to the terminal velocity of the larger ice particle, which allowed for less time for sintering to take place than our experiments. Hobbs (1965) has shown that the ice "neck" forming during the sintering process between two ice particles is proportional to the length of time that they are in contact.

In our experiments ice crystals initially fall together at very similar speeds and so can come together for longer, thus allowing sintering to take place. In some regions of the atmosphere this is more realistic than the experiments performed by Hosler and Halgren (1960), for example in young cirrus where ice crystals are growing by vapour diffusion and are approximately the same size (and hence have the same fallspeeds). Indeed images of aggregates taken by CPI probes on an aircraft tend to show that aggregates are comprised of ice crystals that are similar in size (Connolly et al., 2005; Gallagher et al., 2005; Whiteway et al., 2004), although this statement is not completely general. 


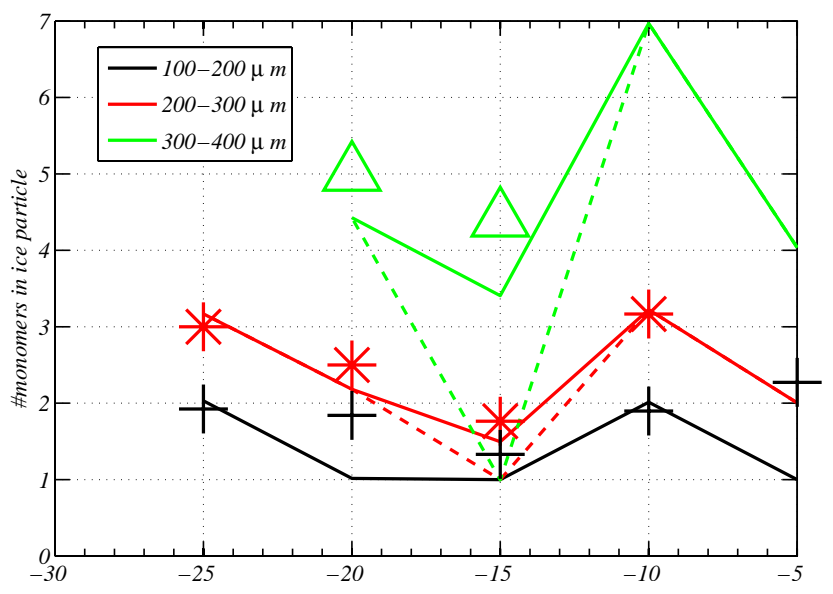

Fig. 16. A comparison of the number of monomer ice crystals in each of the size ranges: $100-200 \mu \mathrm{m} ; 200-300 \mu \mathrm{m}$; and 300 $400 \mu \mathrm{m}$. The solid lines are those modelled using the best guess value of $E_{\text {agg }}$ in Fig. 14b, while dashed lines are those modelled using the best guess value of $E_{\text {agg }}$ in Fig. 14a. Note that the dash black line lies on top of the black solid line because the only difference between the two $E_{\text {agg }}$ representations are at $-15^{\circ} \mathrm{C}$, where both y-values are zero. Symbols are those measured using the CPI images. Note that the $E_{\text {agg }}$ shown in Fig. 14a underestimates the number of monomers in all size bins at $-15^{\circ} \mathrm{C}$, because the ice crystals grow too large by vapour diffusion and grow to larger sizes than the size bins shown.

Since the height over which the ice crystals were able to aggregate in our experiments was much smaller than in the atmosphere (typically $\sim 10 \mathrm{~m}$ ) we forced higher aggregation rates than occur in nature by using high number concentrations $\left(\sim 10 \mathrm{~cm}^{-3}\right)$ of ice crystals; this concentration equates to an average spacing between the ice crystals of $\sim 5 \mathrm{~mm}$; therefore, the hydrodynamic kernel should still be applicable in this situation for the same reasons it is applicable for collision and coalescence of water drops.

An important point to raise regarding this study is that although, statistically we can not rule out that the aggregation efficiency is equal to zero for all but the experiment at $-15^{\circ} \mathrm{C}$, we have observed that is must be greater than zero as some aggregates were observed in the CPI images at all temperatures. Therefore this provides a guide for the choice of $E_{\mathrm{agg}}$ in this instance. We have also shown that when comparing the number of monomers per aggregate in the model run to the estimate of the average number of monomers per aggregate in the CPI images we get good agreement between model and data when the best estimate of the aggregation efficiency (the MLE) is used, so this implies that the error bars should be smaller than shown in Fig. 14; however, we can not prove this statistically by using the concentration data alone.

It should be pointed out that our estimate of the aggregation efficiency at $-30^{\circ} \mathrm{C}$, could be subject to experimental artefacts. At this temperature many ice crystals were nucleated that could have been smaller than the $10 \mu \mathrm{m}$ size limit detectable by the CPI placed in the middle of the chamber. Indeed by the time the ice particles had fallen to the bottom of the chamber they were all large enough to be seen by the CPI, but this may mean that we are slightly underestimating the aggregation efficiency at this temperature.

An interesting point is that the aggregation efficiency does not show a marked increase at the highest temperature $\left(-5^{\circ} \mathrm{C}\right)$, whereas it has been shown that the force required to separate two ice spheres increases with increasing temperature (Hosler et al., 1957). This suggests that that aggregation is not strongly governed by the strength of the bond between the two ice crystals, but may depend on them coming together for long enough to experience a slight amount of sintering - growth from the vapour at the point of contact. It may also suggest that interlocking of ice crystals is an important effect that must occur; however, we still saw aggregation occurring for both columnar crystals and simple plates, which suggests that interlocking is not a necessity for aggregation to take place, but likely enhances it. It is true that the aggregation efficiency was largest where dendrites were observed; however, this is also close to the temperature where the maximum vapour excess over an ice surface exists, when the humidity is at water saturation, which also may affect the aggregation efficiency through the sintering mechanism. Further work looking at the narrow temperature region from 0 to $-5^{\circ} \mathrm{C}$ is needed to fully test whether $E_{\text {agg }}$ is maximised at $0^{\circ} \mathrm{C}$.

On balance the fact that the aggregation efficiencies at -10 and $-15^{\circ} \mathrm{C}$ are very different, yet the difference between water and ice vapour pressures are almost exactly the same at these two temperatures, suggests that it is not vapour growth or sintering that is responsible for the maximum at $-15^{\circ} \mathrm{C}$. The fact that the planar crystals observed at $-10^{\circ} \mathrm{C}$ did not have dendrites suggests that interlocking is the likely reason for the maximum in $E_{\text {agg }}$ at $-15^{\circ} \mathrm{C}$.

It may be the case that in the initial stages of growth when the ice crystals are not too complex that aggregation efficiencies similar to those reported by Hosler and Halgren (1960) are appropriate, but when ice crystals start to display branching or contain more than a few monomers higher aggregation efficiencies, $\sim 0.6$, are more appropriate.

We have avoided simplifying the microphysical scheme to bulk microphysics to attempt to model the aggregation process (as done by Passarelli, 1978; Mitchell, 1988, 1991), since we found that: (i) the input parameters to this model, such as the mass-dimension and terminal velocity-dimension relations have significant uncertainties and the model was very sensitive to them in determining the value of $E_{\text {agg }}$; and (ii) the experiment was not always in steady state with height, which the more simple model assumes. Therefore we used a more sophisticated bin model, which explicitly includes differential sedimentation, for interpretation herein. 


\section{Conclusions}

Ice crystal aggregation efficiencies were derived from experimental studies using a cloud chamber in the temperature interval $-30 \leq T \leq-5^{\circ} \mathrm{C}$ for the case where the ice crystals were growing at water saturated conditions. The aggregation efficiencies shown in Fig. 14 should be valid for the case of small ice crystals in the initial stages of aggregation and we suggest that in this case the interlocking mechanism is important to enhancing the sintering upon contact mechanism. When the ice particles become larger and more complex one could hypothesize that the interlocking mechanism becomes important at all temperatures, but this requires further study.

Several conclusions can be drawn from this study, they are:

- In order to effectively model the aggregation process in a 1-D column model we could not apply the commonly used single moment advection schemes and had to adopt a double moment bin structure. If we used the single moment scheme we would see artificial spreading out (diffusion) of the number concentration field and therefore considerably underestimate the aggregation efficiencies because the concentration peak would reduce rapidly even for model runs with $E_{\mathrm{agg}}=0$.

- We tried interpreting the data with bulk microphysical theory (Mitchell, 1988, 1991) and found it to be sensitive to the assumed parameters in the mass-dimension and terminal velocity-dimension relations of the ice crystals. Furthermore, it was difficult to set up with the measurements here as the snow growth model requires an input profile of the ice water content, which we did not measure. Instead we opted to use a sophisticated bin microphysics model, which does not use a terminal velocity-dimension relation, uses prognostic variables to estimate the mass-size relation and considers differential sedimentation. The bin microphysics model does not require initialisation with an ice water content profile.

- Using the bin microphysical model to interpret the results gives us a best estimate of the aggregation efficiency that is close to those published by Hosler and Halgren (1960) except at $-15^{\circ} \mathrm{C}$ where we saw significantly higher aggregation efficiencies. We believe our error bars in Fig. 14 may be overly conservative; however, unfortunately we can not provided statisticallybased evidence for this statement. It is noted that Hobbs et al. (1974) also inferred a maximum in aggregation efficiency at $-15^{\circ} \mathrm{C}$ from data taken from natural clouds in the Cascade Mountains. This was attributed to the intricate structure of dendrites in this region.

- In order to reduce the error bars on the estimates of $E_{\text {agg }}$ it may be necessary to produce higher concentrations of crystals at the top of the chamber so that more aggregation takes place over the $10 \mathrm{~m}$ height of the chamber.
However, a caveat is that this results in less growth of the crystals by vapour diffusion.

- We also found that the aspect ratios of the ice crystals grown in the experiments was inconsistent with those predicted by the Chen and Lamb (1994a) scheme and so had to adjust the inherent growth ratio parameter somewhat arbitrarily so that the actual crystal aspect ratio was reproduced within the model. We have no explanation for why this occurred except that factors occurring at the point of nucleation may affect the habit of the ice crystals produced (Bacon et al., 2003), or that the fact that the crystals were growing whilst in free-fall, as occurs in nature, could have affected the habit they grew into.

It was not possible to address other aspects of ice crystal growth by aggregation in these experiments, which given further resources and time maybe useful to try and quantify, such as:

- How does the aggregation efficiency depend on the supersaturation over ice? Presumably if vapour growth between two ice crystals that come together is important then the supersaturation should affect the aggregation efficiency.

- How complex do ice particles need to be so that interlocking of crystal branches or other spatial features becomes important? Does this effectively mean that once crystals contain more than just a few monomers their aggregation efficiency becomes much closer to unity?

However, we believe that the study is relevant for shallow mixed-phase layer clouds, where the ice crystal size usually is not so large and the temperature is within the range of our experiments.

\section{Appendix A}

\section{Correction of Cloud Particle Imager data}

We used the depth-of-field (DOF) correction devised by Connolly et al. (2007) to correct for biases in the sizing and sample volume for both CPIs. We note that there is an error in the original paper that defines the calibration curve (Eq. 7 in the original paper). The correct equation should read:

$$
\frac{L_{\text {app }}}{L}=\left(d_{1} \times\left\{\left|\frac{Z}{\left(L A_{r}\right)^{2}}\right|+d_{2} \frac{Z}{\left(L A_{r}\right)^{2}}\right\}^{d_{3}} \times \frac{\mathrm{BG}_{\mathrm{loc}}}{\overline{\mathrm{BG}}}+d_{4} L^{d_{5}}\right)
$$

all fit parameters are as quoted in the original paper and the correct equation was used in the analysis so the results of Connolly et al. (2007) remain valid. 


\section{Appendix B}

\section{Fit to gamma distribution functions}

In order to fit the CPI data to gamma distribution functions we start with definitions for the 1st, 2nd and 6th moment of a gamma distribution:

$M_{1}=\int n_{0} D^{\mu+1} \exp (-\lambda D) d D=\frac{n_{0} \Gamma(\mu+2)}{\lambda^{\mu+2}}$
$M_{2}=\int n_{0} D^{\mu+2} \exp (-\lambda D) d D=\frac{n_{0} \Gamma(\mu+3)}{\lambda^{\mu+3}}$
$M_{6}=\int n_{0} D^{\mu+6} \exp (-\lambda D) d D=\frac{n_{0} \Gamma(\mu+7)}{\lambda^{\mu+7}}$

If exponential fits are adequate (i.e. $\mu=0$ ) then the step of determining $\mu$ can be skipped, otherwise we have to calculate the variable, $F=\frac{M_{2}^{5}}{M_{6} M_{1}^{4}}$, which yields:

$F=\frac{n_{0}^{5} \Gamma(\mu+3)^{5} \lambda^{\mu+7}\left(\lambda^{\mu+2}\right)^{4}}{\left(\lambda^{\mu+3}\right)^{5} n_{0} \Gamma(\mu+7) n_{0}^{4} \Gamma(\mu+2)^{4}}$

Using the identity $\Gamma(\mu+1)=\mu \Gamma(\mu)$ we can simplify Eq. (B4) to

$$
F=\frac{(\mu+2)^{4}}{(\mu+7)(\mu+6)(\mu+5)(\mu+4)(\mu+3)}
$$

Which is a quartic polynomial in $\mu$ :

$$
\begin{aligned}
& (1-F) \mu^{4}+(8-18 F) \mu^{3}+(24-119 F) \mu^{2} \\
& +(32-342 F) \mu+(16-360 F)=0
\end{aligned}
$$

In order to evaluate each of the coefficients in the above polynomial $F$ is calculated from the actual size distribution data and substituted accordingly. The quartic equation is then solved for $\mu$ using a numerical algorithm. Once $\mu$ is known or indeed if $\mu$ is assumed to be zero then $\lambda$ is determined by taking the ratio of either of the moments, for example:

$\frac{M_{1}}{M_{2}}=\frac{\lambda \Gamma(\mu+2)}{\Gamma(\mu+3)}$

and therefore

$\lambda=\frac{M_{1}}{M_{2}} \frac{\Gamma(\mu+3)}{\Gamma(\mu+2)}$

$n_{0}$ may then be determined by substitution of $\lambda$ and $\mu$ in the expression for one of the moments, for example using $M_{1}$ :

$n_{0}=\frac{M_{1} \lambda^{\mu+2}}{\Gamma(\mu+2)}$

Thus both the slope and intercept can be found in this way.

Note that the equation for $\lambda$ can also be written down in terms of the zeroth and 2nd moments of the distribution since

$M_{0}=\int n_{0} D^{\mu} \exp (-\lambda D) d D=\frac{n_{0} \Gamma(\mu+1)}{\lambda^{\mu+1}}$ so that:

$M_{1}=\frac{M_{0}}{\lambda} \times \frac{\Gamma(\mu+2)}{\Gamma(\mu+1)}$

and therefore:

$\lambda=\left(\frac{M_{0}}{M_{2}} \frac{\Gamma(\mu+3)}{\Gamma(\mu+1)}\right)^{1 / 2}$

This shows that increasing mass (the 2nd moment), while maintaining number (zeroth moment) results in a reduction in $\lambda$. Furthermore, holding the mass constant (the 2nd moment), while reducing number (zeroth moment) also reduces $\lambda$. So the microphysical growth processes of vapour diffusion and aggregation both result in a reduction of $\lambda$ with time; however, differential sedimentation may result in an increase in $\lambda$ with time (not shown).

Acknowledgements. This work was funded by the Natural Environment Research Council (NERC) under the grant code NE/G000875/1. Additionally, we thank Peter Kelly for his assistance in engineering multiple aspects of the experimental equipment used in this research. Further acknowledgement is given to the NERC Facility for Ground-based Atmospheric Measurements (FGAM) for providing the CPI instruments used to generate the data for this study. The first and second author would like to acknowledge the invaluable help of the following UoM undergraduate project students in initial analysis that were used to refine the analysis reported in this paper: Daniel Rounds, Jennifer Cronin, Rachel Walsh and Douglas Finch.

Edited by: D. J. Cziczo

\section{References}

aufm Kampe, H. J., Weickmann, H. K., and Kelly, J. J.: The influence of temperature on the shape of ice crystals growing at water saturation, J. Meteorol., 8, 168-174, 1951.

Bacon, N. J., Baker, M. B., and Swanson, B. D.: Initial stages in the morphological evolution of vapour-grown ice crystals: A laboratory investigation, Q. J. Roy. Meteor. Soc., 129, 1903-1927, 2003.

Bailey, M. and Hallett, J.: Growth Rates and Habits of Ice Crystals between $-20^{\circ} \mathrm{C}$ and $-70^{\circ} \mathrm{C}$, J. Atmos. Sci., 61, 514-544, 2004.

Bailey, M. and Hallett, J.: A comprehensive habit diagram for atmospheric ice crystals: Confirmation from the laboratory, AIRS II, and other field studies, J. Atmos. Sci., 66, 2888-2899, 2009.

Bott, A.: A positive definite advection scheme obtained by nonlinear renormalization of the advective fluxes, Mon. Weather Rev., 117, 1006-1015, 1989.

Bott, A.: Monotone flux limitation in the area-preserving flux-form advection algorithm, Mon. Weather Rev., 120, 2592-2602, 1992.

Bott, A.: A flux method for the numerical solution of the stochastic collection equation: Extension to two-dimensional particle distributions, J. Atmos. Sci., 57, 284-294, 2000.

Bott, A., Sievers, U., and Zdunkowski, W.: A radiation fog model with a detailed treatment of the interaction between radiative 
transfer and fog microphysics, J. Atmos. Sci., 47, 2153-2166, 1990.

Chen, J.-P. and Lamb, D.: The The oretical Basis for the Parameterisation of Ice Crystal Habits: Growth by Vapour Deposition, J. Atmos. Sci., 51, 1206-1221, 1994a.

Chen, J.-P. and Lamb, D.: Simulation of cloud microphysical and chemical processes using a multicomponent framework. Part I: Description of the microphysical model, J. Atmos. Sci., 51, 2613-2630, 1994b.

Connolly, P. J., Saunders, C. P. R., Gallagher, M. W., Bower, K. N., Flynn, M. J., Choularton, T. W., Whiteway, J., and Lawson, P.: Aircraft Observations of the influence of electric fields on the aggregation of ice crystals, Q. J. Roy. Meteor. Soc., 131, 16951712, 2005.

Connolly, P. J., Flynn, M. J., Ulanowski, Z., Choularton, T. W., Gallagher, M. W., and Bower, K. N.: Calibration of the Cloud Particle Imager Probes using Calibration beads and Ice Crystal Analogs: The depth-of-field, J. Atmos. Ocean. Technol., 24, 1860-1879, 2007.

Connolly, P. J., Möhler, O., Field, P. R., Saathoff, H., Burgess, R., Gallagher, M. W., and Choularton, T. W.: Studies of ice nucleation on three different types of dust particle, Atmos. Chem. Phys., 9, 2805-2824, doi:10.5194/acp-9-2805-2009, 2009.

Costa, A. A. and Sampaio, A. J. C.: Bott's area-preserving flux form advection algorithm: extension to higher orders and additional tests, Mon. Weather Rev., 125, 1983-1989, 1997.

Crosier, J., Bower, K. N., Choularton, T. W., Westbrook, C. D., Connolly, P. J., Cui, Z., Crawford, I., Capes, G., Coe, H., Dorsey, J. R., Williams, P. I., Illingworth, A. J., Gallagher, M. W., and Blyth, A. M.: Observations of ice multiplication in a weakly convective cell embedded in supercooled mid-level stratus, Atmos. Chem. Phys., 11, 257-273, doi:10.5194/acp-11-257-2011, 2011.

Dearden, C.: Investigating the simulation of cloud microphysical processes in numerical models using a one-dimensional dynamical frameword., Atmos. Sci. Lett., 10, 207-214, 2009.

Dearden, C., Connolly, P. J., Choularton, T. W., and Field, P. R.: Evaluating the effects of microphysical complexity in idealised simulations of trade wind cumulus using the Factorial Method, Atmos. Chem. Phys., 11, 2729-2746, doi:10.5194/acp-11-27292011, 2011.

Field, P. R. and Heymsfield, A. J.: Aggregation and scaling of ice crystal size distributions, J. Atmos. Sci., 60, 544-560, 2003.

Field, P. R., Wood, R., Brown, P. R. A., Kaye, P. H., Hirst, E., Greenaway, R. S., and Smith, J. A.: Ice particle interarrival times measured with a fast FSSP, J. Atmos. Ocean. Technol., 20, 249261, 2003

Field, P. R., Heymsfield, A. J., and Bansemer, A.: Shattering and particle Interarrival times measured by optical array probes in ice clouds, J. Atmos. Ocean. Technol., 23, 1357-1371, 2006a.

Field, P. R., Heymsfield, A. J., and Bansemer, A.: A test of ice selfcollection kernels using aircraft data, J. Atmos. Sci., 63, 651$666,2006 \mathrm{~b}$

Field, P. R., Heymsfield, A. J., and Bansemer, A.: Snow Size Distribution Parameterization for Midlatitude and Tropical Ice Clouds, J. Atmos. Sci., 64, 4346-4365, 2007.

Gallagher, M. W., Whiteway, J., Flynn, M. J., Connolly, P. J., Figueros-Nieto, D., Choularton, T. W., Bower, K. N., Cook, C., Busen, R., and Hacker, J.: An overview of the microphysical structure of cirrus clouds observed during EMERALD-1, Q. J.
Roy. Meteor. Soc., 131, 1143-1169, 2005.

Hall, W. D.: A detailed microphysical model within a twodimensional dynamical framework: model description and preliminary results, J. Atmos. Sci., 37, 2486-2507, 1980.

Heymsfield, A. J.: Ice Particle Evolution in the Anvil of a Severe Thunderstorm during CCOPE, J. Atmos. Sci., 43, 2463-2478, 1986.

Heymsfield, A. J. and Westbrook, C. D.: Advances in the estimation of ice particle fall speeds using laboratory and field measurements, J. Atmos. Sci., 67, 2467-2482, 2010.

Hobbs, P. V.: Aggregation of ice particles in clouds and fogs at low temperatures, J. Atmos. Sci., 22, 296-300, 1965.

Hobbs, P. V., Chang, S., and Locatelli, J. D.: The dimensions and aggregation of ice crystals in natural clouds, J. Geophys. Res., 79, 2199-2206, 1974.

Hosler, C. L. and Halgren, R. E.: The aggregation of small ice crystals, Faraday Discuss., 30, 200-206, 1960.

Hosler, C. L., Jensen, D. C., and Goldshlak, L.: On the aggregation of ice crystals to form snow, J. Meteorol., 14, 415-420, 1957.

Jacobson, M. Z.: Fundamentals of atmospheric modelling, Cambridge University Press, New York, USA, 1999.

Ji, W. and Wang, P. K.: Ventilation coefficients for falling ice crystals in the atmosphere at low intermediate Reynolds numbers, J. Atmos. Sci., 56, 829-836, 1999.

Kovetz, A. and Olund, B.: The effect of coalescence and condensation on rain formation in a cloud of finite vertical extent, J. Atmos. Sci., 26, 1060-1065, 1969.

Lawson, R. P.: Effects of ice particles shattering on the 2D-S probe, Atmos. Meas. Tech., 4, 1361-1381, doi:10.5194/amt-4-13612011, 2011.

Libbrecht, K. G.: The physics of snow crystals, Reports on progress in physics, 68, 855-895, 2005.

Lo, K. and Passarelli, R. E.: The growth of snow in winter storms: an airborne observational study, J. Atmos. Sci., 39, 697-706, 1982.

McFarquhar, G. M., Junshik, U., Freer, M., Baumgardner, D., Kok, G. L., and Mace, G.: Importance of small ice crystals to cirrus properties: Observations from the Tropical Warm Pool International Cloud Experiment (TWP-ICE), Geophys. Res. Lett., 34, L13803, doi:10.1029/2007GL029865, 2007.

Mitchell, D.: Evolution of snow-size spectra in cyclonic storms. Part I: Snow growth by vapour deposition and aggregation, J. Atmos. Sci., 45, 3431-3451, 1988.

Mitchell, D.: Evolution of snow-size spectra in cyclonic storms. Part II: Deviations from the exponential form, J. Atmos. Sci., 48, 1885-1899, 1991.

Mitchell, D., Chai, S., Liu, Y., Heymsfield, A. J., and Dong, Y. Y.: Modeling cirrus clouds. Part I: Treatment of bimodal size spectra and case study analysis, J. Atmos. Sci., 53, 2952-2966, 1996.

Mitchell, D., Huggins, A., and Grubisic, V.: A new snow growth model with application to radar precipitation schemes, Atmos. Res., 82, 2-18, 2006.

Passarelli, R. E.: An approximate analytical model of the vapor deposition and aggregation growth of snowflakes, J. Atmos. Sci. 35, 118-124, 1978.

Pruppacher, H. R. and Klett, J. D.: Microphysics of clouds and precipitation, "Kluwer Academic Press", "Norwell", 1997.

Pruppacher, H. R. and Rasmussen, R. M.: Wind-tunnel investigation of the rate of evaporation of large water drops falling at ter- 
minal velocity in air, J. Atmos. Sci., 36, 1255-1260, 1979.

Schmitt, C. and Heymsfield, A. J.: The dimensional characteristics of ice crystal aggregates from fractal geometry, J. Atmos. Sci., 67, 1605-1616, 2010.

Schwarzenboeck, A., Shcherbakov, V., Lefevre, R., Gayet, J.-F., Pointin, Y., and Duroure, C.: Indications for stellar-crystal fragmentation in Arctic clouds, Atmos. Res., 92, 220-228, 2009.

Sölch, I. and Kärcher, B.: Process-oriented large-eddy simulations of a midlatitude cirrus cloud system based on observations, Q. J. Roy. Meteor. Soc., 137, 374-393, 2011.

Topping, D. O., McFiggans, G. B., and Coe, H.: A curved multcomponent aerosol hygroscopicity model framework: Part 1 - Inorganic compounds, Atmos. Chem. Phys., 5, 1205-1222, doi:10.5194/acp-5-1205-2005, 2005a.

Topping, D. O., McFiggans, G. B., and Coe, H.: A curved multicomponent aerosol hygroscopicity model framework: Part 2 Including organic compounds, Atmos. Chem. Phys., 5, 1223$1242,2005 b$.
Westbrook, C. D., Ball, R. C., Field, P. R., and Heymsfield, A. J.: Universality in snowflake aggregation, Geophys. Res. Lett., 31, L15104, doi:10.1029/2004GL020363, 2004.

Westbrook, C. D., Hogan, R. J., and Illingworth, A. J.: The capacitance of pristine ice crystals and aggregate snowflakes, J. Atmos. Sci., 65, 206-219, 2008.

Whiteway, J., Choularton, T. W., Harries, J., Cook, C., Gallagher, M. W., Connolly, P. J., Busen, P., Bower, K. N., Flynn, M. J., May, P., and Hacker, J.: Anatomy of cirrus clouds: results from the EMERALD Airborne campaigns, Geophys. Res. Lett., 31, 24102-24105, 2004. 